\title{
A Positive Iris Feedback: Insights from Climate Simulations with Temperature-Sensitive Cloud-Rain Conversion 0
}

\author{
R. L. LI \\ Department of Geology and Geophysics, Yale University, New Haven, Connecticut \\ T. STORELVMO \\ Department of Geosciences, University of Oslo, Oslo, Norway \\ A. V. FEDOROV ${ }^{\mathrm{a}}$ \\ Department of Geology and Geophysics, Yale University, New Haven, Connecticut \\ Y.-S. CHOI \\ Department of Environmental Science and Engineering, Ewha Womans University, Seoul, South Korea
}

(Manuscript received 9 December 2018, in final form 28 May 2019)

\begin{abstract}
Estimates for equilibrium climate sensitivity from current climate models continue to exhibit a large spread, from 2.1 to $4.7 \mathrm{~K}$ per carbon dioxide doubling. Recent studies have found that the treatment of precipitation efficiency in deep convective clouds - specifically the conversion rate from cloud condensate to rain $C_{p}$ - may contribute to the large intermodel spread. It is common for convective parameterization in climate models to carry a constant $C_{p}$, although its values are model and resolution dependent. In this study, we investigate how introducing a potential iris feedback, the cloud-climate feedback introduced by parameterizing $C_{p}$ to increase with surface temperature, affects future climate simulations within a slab ocean configuration of the Community Earth System Model. Progressively stronger dependencies of $C_{p}$ on temperature unexpectedly increase the equilibrium climate sensitivity monotonically from 3.8 to up to $4.6 \mathrm{~K}$. This positive iris feedback puzzle, in which a reduction in cirrus clouds increases surface temperature, is attributed to changes in the opacity of convectively detrained cirrus. Cirrus clouds reduced largely in ice content and marginally in horizontal coverage, and thus the positive shortwave cloud radiative feedback dominates. The sign of the iris feedback is robust across different cloud macrophysics schemes, which control horizontal cloud cover associated with detrained ice. These results suggest a potentially strong but highly uncertain connection among convective precipitation, detrained anvil cirrus, and the high cloud feedback in a climate forced by increased atmospheric carbon dioxide concentrations.
\end{abstract}

\section{Introduction}

Clouds are of fundamental importance in the global hydrological cycle and radiation budget. Relative to clear-sky conditions, clouds decrease the amount of

Supplemental information related to this paper is available at the Journals Online website: https://doi.org/10.1175/JCLI-D-180845.s1.

${ }^{a}$ Additional affiliation: LOCEAN/IPSL, Sorbonne University, Paris, France.

Corresponding author: Ryan L. Li, ryan.li@yale.edu shortwave (SW) radiation reaching the surface and increase the amount of trapped longwave (LW) radiation. In the global mean, the top-of-atmosphere (TOA) SW cooling $\left(\sim-50 \mathrm{~W} \mathrm{~m}^{-2}\right)$ and $\mathrm{LW}$ warming $\left(\sim 30 \mathrm{~W} \mathrm{~m}^{-2}\right)$ sum to the net cloud radiative effect (CRE) of about $-20 \mathrm{~W} \mathrm{~m}^{-2}$ (Allan 2011). The CRE can respond to an external forcing, for example, increased atmospheric greenhouse gas concentrations, which results in an internal feedback process that can either amplify or dampen the forcing. For example, if all clouds reflected less SW radiation in a warmer climate, that would induce further warming and thus be a positive feedback. Owing to the dependence of clouds on processes that cannot be resolved on the typical scales of global climate models 
(GCMs), clouds must be parameterized, often on the basis of empirical relationships between cloud properties and resolved variables that represent a large source of uncertainty (e.g., Gettelman et al. 2010; Song et al. 2012). Partly for this reason, the cloud-climate feedback continues to inhibit our understanding of the sensitivity of the climate to radiative forcing (e.g., Sherwood et al. 2014, Bony et al. 2015).

Equilibrium climate sensitivity (ECS) quantifies the global mean surface warming response to doubling of atmospheric carbon dioxide $\left(\mathrm{CO}_{2}\right)$, after the climate system reaches a new equilibrium (e.g., Cox et al. 2018). An updated review from the Intergovernmental Panel on Climate Change (IPCC) Fifth Assessment Report (AR5) estimates the ECS to be between 1.5 and $4.5 \mathrm{~K}$ (Flato et al. 2013), the same range as that given by the Charney report almost four decades ago (Charney et al. 1979). The lower bound is higher in the 2.1-4.7-K multimodel range, from the most recent phase of the Climate Model Intercomparison Project (CMIP5; Taylor et al. 2012). The Planck feedback $\left(-3.2 \mathrm{~W} \mathrm{~m}^{-2} \mathrm{~K}^{-1}\right)$, water vapor/lapse rate feedback $\left(1.0 \mathrm{~W} \mathrm{~m}^{-2} \mathrm{~K}^{-1}\right)$, and snow/ice albedo feedback $\left(0.3 \mathrm{~W} \mathrm{~m}^{-2} \mathrm{~K}^{-1}\right)$ are all well understood and constrained across the CMIP5 multimodel mean. However, cloud feedback estimates from the Cloud Feedback Model Intercomparison Project (CFMIP) have an intermodel spread of $0.2-$ $1.4 \mathrm{~W} \mathrm{~m}^{-2} \mathrm{~K}^{-1}$. Combining the radiative forcing of $\mathrm{CO}_{2}$ doubling $\left(3.7 \mathrm{~W} \mathrm{~m}^{-2}\right)$ with the well-known climate feedbacks, the lower and upper bounds of the cloud feedback range span almost the entire CMIP5 ECS range (Bretherton 2015), isolating clouds as the dominant contributor to the spread. IPCC AR5 estimates the cloud feedback to be +0.6 (from -0.2 to +2.0 ) $\mathrm{W} \mathrm{m}{ }^{-2} \mathrm{~K}^{-1}$, with broader ranges to account for cloud processes that may be missing in models (Boucher et al. 2013). Thus, narrowing the range for plausible cloud feedbacks, and particularly ruling out the possibility of a net negative cloud feedback, would place an important and urgently needed constraint on ECS estimates (Zelinka et al. 2016).

One of the most robust cloud feedbacks is the positive cloud altitude feedback associated with rising of the tropopause as the planet warms (Ceppi et al. 2017). Cirrus clouds emit infrared radiation according to their cloud top temperature and warm the troposphere by an enhanced greenhouse effect that depends primarily on the temperature difference between the surface and cloud top. Hartmann and Larson (2002) connect subsidence warming, radiatively driven convergence, and the altitude of anvil clouds to the clear-sky radiative cooling rate in the tropics and provide a firm physical basis for the robust cloud feedback. They show that the cloud top temperature of tropical anvil cirrus tends to remain fixed. As a result, the warming effect of these clouds will increase with rising surface temperatures. Thompson et al. (2017) argue that this fixed anvil temperature hypothesis that constrains the depth of the tropopause and temperature of high clouds also applies globally. This rising cloud top phenomenon is supported by GCMs (e.g., Wetherald and Manabe 1980), highresolution cloud-resolving simulations (e.g., Satoh et al. 2012), and satellite-derived observations (Norris et al. 2016). The fixed anvil temperature feedback is estimated to contribute about $0.3-0.4 \mathrm{~W} \mathrm{~m}^{-2} \mathrm{~K}^{-1}$ to the cloud feedback predicted by CMIP5 models (Zelinka et al. 2012a) and does not differ significantly among GCMs.

As climate models continue to have deficiencies in simulating low clouds, a disagreement in the simulated low cloud response to warming globally explains about $50 \%$ of the intermodel spread in the overall cloud feedback (Zelinka et al. 2016). These clouds involve full interactions between parameterized processes of cloud physics, radiative transfer, boundary layer turbulence, and convection, which are all imperfect (Klein et al. 2017). Furthermore, these clouds, typically located in the lowermost few kilometers of the atmosphere, have large SW but negligible LW radiative effects. As a result, even small changes in their fractional coverage may have a significant impact on the net CRE and climate sensitivity. Bretherton (2015) summarized four mechanisms linked to water vapor increase that impact nonraining clouds over subtropical oceans in highresolution large-eddy simulations. Although similar studies to Bretherton (2015) reveal the dominant mechanisms and provide strong evidence that the low cloud feedback is positive, most do not provide a quantitative constraint on its magnitude (Gettelman and Sherwood 2016). Sherwood et al. (2014) use a lower bound constraint on the low cloud feedback through mixing processes in the lower troposphere and suggest that models that predict an ECS higher than $3 \mathrm{~K}$ are consistent with observations. Similar to low subtropical clouds, tropical deep convective clouds have a strong SW CRE but small horizontal extent, and they are also strongly coupled with high-altitude anvil clouds near the tropopause that have SW and LW CREs that are both strong (Hartmann and Berry 2017).

In the deep tropics, the atmosphere is dominated by regions of large-scale ascent and dry regions of subsidence. The former, associated with latent heat release by convective clouds forced by solar heating, is balanced by radiative cooling in the latter (Fig. 1). Such balance has been proposed to change in favor of dry and clear regions in a warmer climate, for example through the tendency of convective clouds to self-aggregate (e.g., 


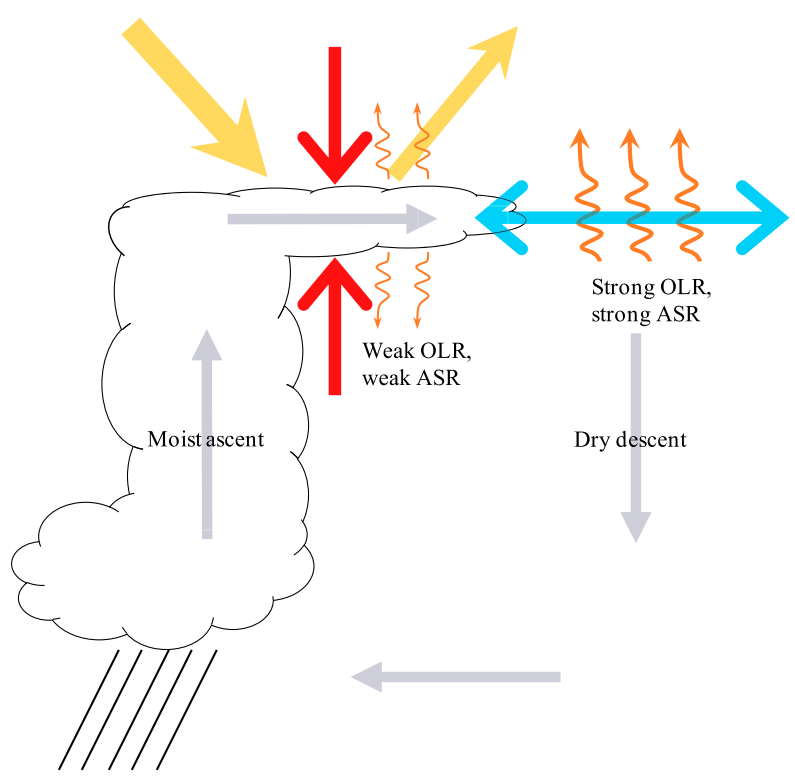

FIG. 1. Energy balance for a tropical deep convective cloud and its neighboring subsiding regions. Gray arrows outline the largescale circulation. Longwave and shortwave radiation are illustrated by orange or yellow arrows, respectively. The feedback associated with a reduction in anvil clouds is a combination of the retreat of horizontal cover (blue) and optical thinning (red).

Muller and Bony 2015; Wing and Emanuel 2014). This cloud clustering mechanism has been detected in radiative-convective equilibrium models that explicitly resolve cloud processes. Although the physics of cloud clustering is not well understood, it has been hypothesized to occur at high surface temperatures. This organization of convective clouds may in turn reduce total cloud cover and detrained anvil ice clouds in a warmer climate (Bony et al. 2016).

The existence of a potential cloud feedback in the tropics was first hypothesized on the basis of observations of upper-level cloud-cover changes with underlying sea surface temperatures (SSTs) over the western Pacific Ocean warm pool (Lindzen et al. 2001). Upper-level cloud cover was found to decrease by about $22 \%$ per degree of warming, suggesting a potentially powerful negative feedback associated with a reduction in area coverage of thin cirrus clouds (Lindzen et al. 2001), which on average have a net warming effect on the climate system. This "iris effect," named after the iris in a human eye, which contracts in the presence of bright light, is herein defined specifically as the increase in outgoing longwave radiation (OLR) associated with reduced cirrus cloudiness. An iris effect could also arise from changes in the balance between convective precipitation and cirrus clouds detrained from deep convection. As surface temperatures rise, less moisture would be left to detrain as high clouds if more cloud condensate is converted to rain in the convective updraft. The iris effect, in its original formulation, has remained controversial, and it has been called into question by many scientists (e.g., Hartmann and Michelsen 2002; Lin et al. 2002; Rapp et al. 2005). A number of studies pointed out issues with the evidence provided in Lindzen et al. (2001). Lin et al. (2002) questioned the assumptions of albedo and longwave fluxes for high clouds in Lindzen et al. (2001). Using subsequent observations, they suggest that retreating cloudy-moist areas would reduce the reflected shortwave radiation, which counterbalances the infrared iris for a weak positive feedback. Hartmann and Michelsen (2002) showed that the observational data used in Lindzen et al. (2001) did not necessarily support the iris hypothesis and offered another interpretation-that the reduced cirrus clouds were from the subtropics, which were away from and unrelated to tropical SST anomalies.

Nevertheless, based on regression analyses of observed cloud fraction, radiative fluxes, and rainfall rates on SST in the tropics, Choi et al. (2017) suggested that satellite-derived observations are consistent with the iris hypothesis. They found notable negative correlations between cirrus cloud fraction and SST, which suggest that the cooling processes summarized in Fig. 1 (blue arrows) are intensified with warmer SST. However, whether the suggested feedback in the tropical western Pacific can be representative of all of the tropics (e.g., eastern Pacific with cooler SST) is uncertain. Thus, the sign of the iris effect remains poorly constrained, although recent literature suggest that it may be weakly negative (e.g., Su et al. 2008; Rondanelli and Lindzen 2010; Choi et al. 2017).

An argument against the iris effect is that it lacks a physical mechanism. One hypothesis for a physical mechanism is that warmer temperatures favor aggregated convection (Emanuel et al. 2014). Updrafts are shielded from the dry environment in aggregated convection, allowing a larger fraction of moisture to be rained out and leaving less moisture left to detrain into anvils (Wing et al. 2017). Simulations using cloudresolving models (e.g., Wing and Emanuel 2014) and aquaplanet GCMs (e.g., Bony et al. 2016) have shown that aggregated convection is accompanied by drying of the free troposphere, which would cool the system by reducing the water vapor greenhouse effect and increasing the OLR. On the other hand, Tobin et al. (2012) show from observations that changes in cloudiness and humidity cause large increases in OLR, but absorbed shortwave radiation also increases. As a result of these opposing effects, they suggest that the net 
top-of-atmosphere radiation is relatively insensitive to convective aggregation. While the organization of convection could result in reduced cloud cover and humidity in the upper troposphere in an iris-like precipitation efficiency feedback, it remains unclear whether tropical warming trends would be regulated by such a cloud feedback.

Mauritsen and Stevens (2015, hereinafter MS15) revisited the iris effect using modified simulations of the atmospheric component of the Max Planck Institute Earth System Model (MPI-ESM), ECHAM6, coupled to a thermodynamic mixed-layer ocean. In present-day mean climate simulations, they modified the conversion rate from cloud water to rain $C_{p}$ in the deep convective parameterization of the GCM so that $C_{p}$ increased with warmer surface temperatures. They found that this introduced a cloud feedback in ECHAM6 that dampens the temperature response but strengthens the hydrological response to rising atmospheric $\mathrm{CO}_{2}$. However, its magnitude and sign are highly dependent on convective and cloud-macrophysical parameterizations, both of which tend to strongly differ across GCMs.

The present study aims to better understand and constrain the cloud feedbacks that arise from changes to tropical anvil cirrus. Since cloud clustering has been suggested to play a potential role, we begin by investigating the potential cloud feedback that could arise from convective aggregation, in the same form proposed by MS15, using a different GCM with a higher climate sensitivity. A detailed cloud feedback decomposition reveals a potential mechanism for the resulting positive feedback, opposite to that in MS15. Emphasis is placed on the cloud feedback contribution associated with cloud opacity changes to provide an alternative view on an iris feedback mechanism (Fig. 1, red arrows). A summary of the GCM setup is presented in section 2 . The simulated climatology is discussed in section 3 , and a comparison with observations is provided in section 4. The response to a doubling of atmospheric $\mathrm{CO}_{2}$ is discussed in section 5 , incorporating a full cloud feedback decomposition. Section 6 considers alternative ice macrophysics schemes, showing sensitivity experiments designated to investigate the robustness of the sign and magnitude of the introduced feedback through vertical thinning. Further discussion and conclusions are provided in section 7 .

\section{Model setup}

The experiments conducted herein use the National Center for Atmospheric Research (NCAR) Community Earth System Model (CESM), version 1.2.2, a GCM that couples separate model components for the atmosphere, ocean, land, and sea ice (Hurrell et al. 2013). We use the Community Atmosphere Model (CAM), version 5.3, the atmospheric component of CESM, run at a horizontal resolution of $1.9^{\circ}$ latitude by $2.5^{\circ}$ longitude with 30 vertical levels. The highest model level reaches $\sim 2 \mathrm{hPa}(\sim 40 \mathrm{~km})$, with 1200 -m vertical spacing near the tropopause. This vertical resolution is relatively coarse, considering that some studies (e.g., Seiki et al. 2015) suggest that simulating the vertical structure of cirrus requires a resolution of a few hundred meters. However, this is a typical vertical resolution for GCMs, and there appears to be only subtle differences in the vertical structure of cloud fraction and top-of-atmosphere SW and LW CREs between a 30-layer and a 60-layer version of CAM (Richter et al. 2014).

The standard configuration of CAM uses the ZhangMcFarlane deep convection scheme (Zhang and McFarlane 1995), with the dilute plume closure assumption by Neale et al. (2008). The shallow convection parameterization follows Park and Bretherton (2009). The stratiform cloud scheme is handled by two separate components: a macrophysics scheme for gridscale condensation and cloud fraction calculations (Park et al. 2014) and a microphysics parameterization for internal subgrid-scale cloud processes (Morrison and Gettelman 2008). The default ice cloud macrophysics scheme in CAM 5.3 is the modified Slingo (1987) scheme as in Gettelman et al. (2008). Radiative transfer follows the Rapid Radiative Transfer Model for GCMs, described by Iacono et al. (2008). Each simulation is run once with approximately preindustrial atmospheric $\mathrm{CO}_{2}$ concentration $(267 \mathrm{ppm})$ and repeated with doubled preindustrial atmospheric $\mathrm{CO}_{2}$ concentration (534 ppm). CAM5.3 is run with the CFMIP Observation Simulator Package (COSP) to diagnose cloud properties from the model as if observed from satellite sensors (BodasSalcedo et al. 2011), and comparable to data from the International Satellite Cloud Climatology Project (ISCCP; Schiffer and Rossow 1983).

The atmosphere is coupled to a slab ocean model (SOM) to include the thermodynamic effects of the ocean mixed layer. Its spatially varying depth is based on observations of the annual-mean mixed-layer depth (Kiehl et al. 2006). The SOM treats the ocean as motionless and perfectly mixed throughout its depth. To maintain a realistic mean climate, an annually periodic, monthly varying heat flux convergence ( $q$ flux) is prescribed in the mixed-layer ocean. The $q$ flux is an added internal heat source that represents deep ocean exchange and lateral heat transport. Despite the lack of deep ocean dynamics, coupled simulations with the SOM can reproduce the ECS estimated with full ocean dynamics to within 5\% accuracy (Danabasoglu and 
TABLE 1. Outline of conducted GCM simulations. The following simulations are conducted for each case: 1) a 50-yr start-up run,2) a 50 -yr continuation run, and 3) a continuation run with doubled atmospheric $\mathrm{CO}_{2}$ concentration.

\begin{tabular}{lc}
\hline \hline Simulation & \multicolumn{1}{c}{ Description } \\
\hline CESM & Standard "out of the box" CESM1.2.2 and \\
& CAM5.3 coupled simulation with a slab \\
ocean model and the modified Slingo & $(1987)$ ice cloud macrophysics scheme \\
& As above, but with modified convective \\
precipitation following Eq. $(1)$, where \\
IRIS2 \\
$I_{e}=0.2$ \\
As above, but with $I_{e}=0.5$ \\
IRIS5 & As above, but with $I_{e}=1.0 ; C_{p}(T)$ is \\
IRIS10 & doubled per degree of surface warming \\
& [Eq. (1)]
\end{tabular}

Gent 2009). The SOM configuration allows the model to reach TOA radiative equilibrium in about $20 \mathrm{yr}$, thus only requiring a 50-yr simulation to determine the ECS. The $q$ flux approach reduces the need for tuning and ensures a reasonable mean climatological state (Mauritsen et al. 2012).

The conversion rate from cloud water to precipitation $C_{p}$ is altered within deep convective clouds in CAM5.3, following that introduced by MS15:

$$
C_{p}(T)=\left\{\begin{array}{ccc}
C_{0} & \text { if } & T_{s} \leq T_{0} \\
C_{0}\left(1+I_{e}\right)^{\frac{T_{s}-T_{0}}{1 \mathrm{~K}}} & \text { if } & T_{s}>T_{0}
\end{array},\right.
$$

where $C_{0}=2 \times 10^{-3} \mathrm{~m}^{-1}$ is the default conversion rate (Lord et al. 1982), $T_{s}$ is surface temperature, and the reference temperature $T_{0}$ is set to $298 \mathrm{~K}$. The exponent in Eq. (1) is divided by $1 \mathrm{~K}$ and is nondimensionalized. Rate $C_{p}$ serves as the new coefficient in the equation for rainwater in cumulus updrafts as $R_{r}=C_{p} M_{u} l$ (Zhang and McFarlane 1995), where $R_{r}$ is the rain rate, $M_{u}$ is the updraft mass flux, and $l$ is the ensemble mean cloud water. The iris parameter $I_{e}$ is set to 0 for the baseline CESM case, and to $0.2,0.5$, and 1.0 in the respective simulations IRIS2, IRIS5, and IRIS10 (Table 1), allowing us to control the strength of the convective precipitation increase with $T_{s}$ (MS15). In the IRIS simulations, more condensate is precipitated in deep convective updrafts, leaving less cloud condensate left for detrainment at upper levels. Consequently, it is expected that cloudiness aloft will decrease more in IRIS simulations than in CESM per surface warming. The choice of $T_{0}=$ $298 \mathrm{~K}$ confines precipitation changes to within the tropics. Because $C_{p}$ is important for convective parameterization but is not directly observable, it is used as a tuning parameter and varied by two orders of
TABLE 2. Climate variables averaged globally and over low latitudes $\left(30^{\circ} \mathrm{S}-30^{\circ} \mathrm{N}\right.$, shown in parentheses) over the last $30 \mathrm{yr}$ for each simulation with preindustrial atmospheric $\mathrm{CO}_{2}$ concentrations. Vertically integrated cloud cover is shown separately for low (below $700 \mathrm{hPa})$, middle $(700-400 \mathrm{hPa})$, and high $(400-50 \mathrm{hPa})$ clouds. Cloud liquid and ice water paths are integrated vertically from the cloud base to the cloud top.

\begin{tabular}{|c|c|c|}
\hline Case & CESM & IRIS10 \\
\hline$I_{e}$ & 0 & 1.0 \\
\hline Surface temperature $(\mathrm{K})$ & $289.2(299.5)$ & $290.2(300.5)$ \\
\hline SW cloud forcing $\left(\mathrm{W} \mathrm{m}^{-2}\right)$ & $-48.8(-54.2)$ & $-45.5(-47.3)$ \\
\hline LW cloud forcing $\left(\mathrm{W} \mathrm{m}^{-2}\right)$ & $24.2(27.4)$ & $22.5(24.1)$ \\
\hline Low cloud cover $(\%)$ & $41.3(30.3)$ & $41.3(30.8)$ \\
\hline Middle cloud cover (\%) & $26.4(17.8)$ & $25.6(17.0)$ \\
\hline High cloud cover (\%) & $38.6(39.2)$ & $37.6(37.4)$ \\
\hline Total cloud cover $(\%)$ & $62.6(56.5)$ & $62.0(55.7)$ \\
\hline $\begin{array}{l}\text { Convective precipitation } \\
\left(\mathrm{mm} \mathrm{day}^{-1}\right)\end{array}$ & $2.3(3.5)$ & $2.4(3.7)$ \\
\hline Stable precipitation $\left(\mathrm{mm} \mathrm{day}^{-1}\right)$ & $0.8(0.3)$ & $0.9(0.3)$ \\
\hline Total precipitation $\left(\mathrm{mm} \mathrm{day}^{-1}\right)$ & $3.1(3.8)$ & $3.3(4.0)$ \\
\hline Cloud liquid water path $\left(\mathrm{g} \mathrm{m}^{-2}\right)$ & $40.6(44.0)$ & $36.0(33.2)$ \\
\hline Cloud ice water path $\left(\mathrm{g} \mathrm{m}^{-2}\right)$ & $16.3(15.5)$ & $13.1(10.2)$ \\
\hline
\end{tabular}

magnitude (MS15). The simulation with largest increase in $C_{p}$, IRIS10, is within the tuning range of $C_{p}$ in convectively active regions such as the Pacific warm pool (see Fig. S1 in the online supplemental material for a spatial distribution of $C_{p}$ in IRIS10). In the following sections, we use the term "iris feedback" to refer specifically to the cloud-climate feedback that arises from introducing Eq. (1) to the deep convective parameterization. This definition not only includes the potential infrared thermostat, that is, the LW cloud amount feedback in the traditional sense, but additional SW cloud feedback terms that are later shown to be significant.

\section{Preindustrial climatology}

Key global and tropical (defined hereinafter as from $30^{\circ} \mathrm{S}$ to $30^{\circ} \mathrm{N}$ ) mean properties of the preindustrial climate system are shown in Table 2 . The direct change imposed on the system is predominantly an increase in the convective rain rate in the tropics (see Fig. S2 in the supplemental online material for the precipitation change between CESM and IRIS10), confined by the choice of $T_{0}$ in Eq. (1). In perspective, the largest $I_{e}$ scenario, IRIS10, increases tropical mean rainfall by $\sim 65 \mathrm{~mm} \mathrm{yr}^{-1}$. Stable (stratiform) precipitation is also increased slightly, possibly due to rain droplets originating in convective clouds falling through and accreting moisture from stable clouds. This increase in rainfall reduces high cloud cover by $\sim 0.01$ ( $3 \%$ relative reduction), which consequently leads to a change in LW 
CESM

(a)

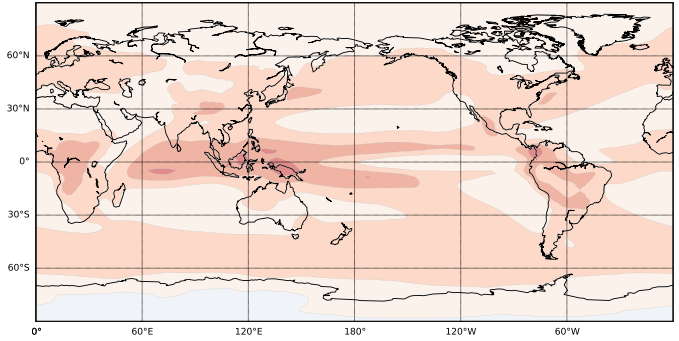

(b)

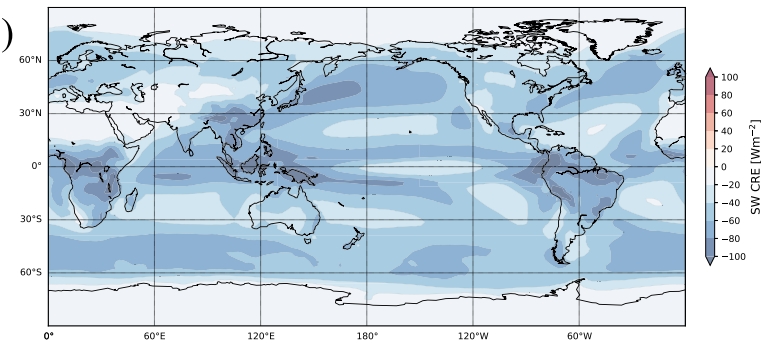

IRIS10 minus CESM

(c)

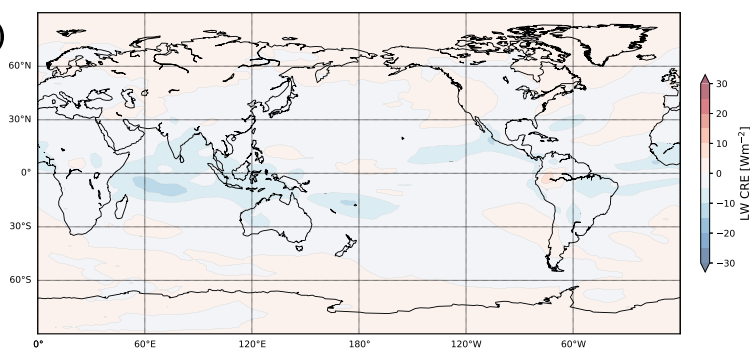

(d)

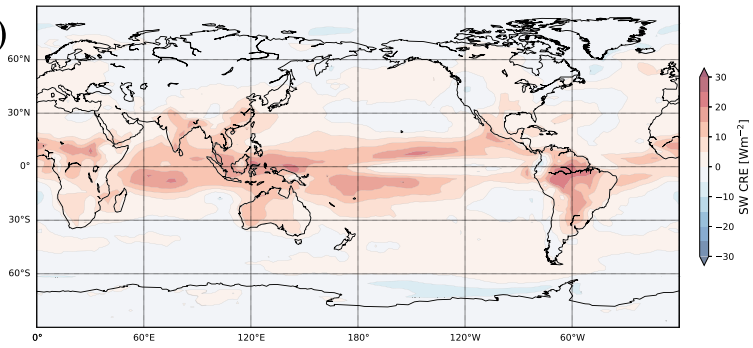

(e)

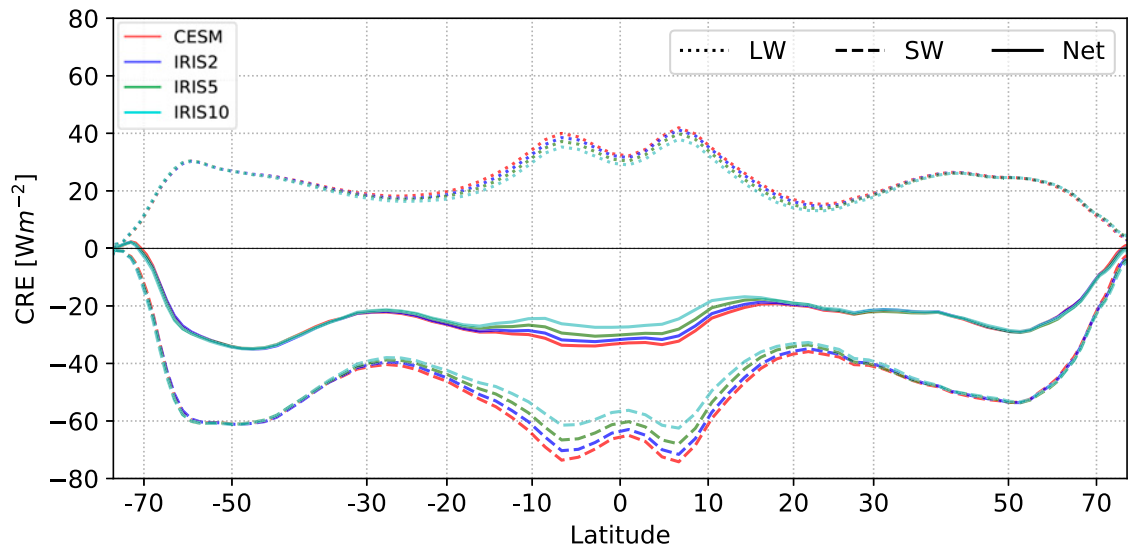

FIG. 2. (a) SW and (b) LW cloud radiative effect averaged over the last $30 \mathrm{yr}$ of the preindustrial CESM simulation. (c),(d) As in (a) and (b), but for IRIS10 minus CESM. (e) Zonal mean SW, LW, and net cloud radiative effects for each case described in Table 1.

CRE of $\sim-1.5 \mathrm{~W} \mathrm{~m}^{-2}$. Interestingly, the change in SW CRE is doubled that of the change in LW CRE $\left(\sim+3 \mathrm{~W} \mathrm{~m}^{-2}\right)$ between IRIS10 and CESM. The corresponding change in the net CRE is positive, which causes the simulations with modified $C_{p}$ to equilibrate to slightly higher global mean surface temperatures relative to CESM.

The spatial patterns of CRE in CESM (Figs. 2a,b) resemble the observed patterns in the present-day climate (Boucher et al. 2013). The differences in LW and SW CRE between the largest $I_{e}$ simulation and CESM are shown in Figs. $2 \mathrm{c}$ and $2 \mathrm{~d}$, respectively. In a distinct latitude band between $30^{\circ} \mathrm{S}$ and $30^{\circ} \mathrm{N}$, the positive difference in SW CRE (dark red patches in Fig. 2d) overwhelms the negative difference in LW CRE (blue patches in Fig. 2c). As a result, the net CRE increases, wherein the overall cooling effect of clouds is reduced, from CESM, IRIS2, IRIS5, to IRIS10 (Fig. 2e, solid lines). Thus, the increased precipitation efficiency simulations reach a higher mean surface temperature. The global mean surface temperature is $1 \mathrm{~K}$ warmer in IRIS10 compared to CESM (Table 2). Part of the difference in CRE introduced by Eq. (1) is due to changes in cloud cover. The global reduction in cloud fractional cover is larger for mid- to high-level clouds (Table 3; a $1 \%$ absolute difference between IRIS10 and CESM), and small for low clouds. The tropical and global trends are similar, confirming that the changes to CRE are primarily due to a tropical signal. The CRE change is also partly caused by the change in the gridbox averaged liquid water path (LWP) and ice water path (IWP), which are reduced by approximately $11.5 \%$ and $19.5 \%$, 
TABLE 3. As in Table 2, but responses per $\mathrm{CO}_{2}$ doubling (doubled minus preindustrial $\mathrm{CO}_{2}$ ).

\begin{tabular}{lcc}
\hline \multicolumn{1}{c}{ Case } & CESM & IRIS10 \\
\hline$I_{e}$ & 0 & 1.0 \\
Surface temperature (K) & $3.8(2.7)$ & $4.6(3.6)$ \\
SW cloud forcing $\left(\mathrm{W} \mathrm{m}^{-2}\right)$ & $1.5(1.3)$ & $4.6(6.5)$ \\
LW cloud forcing $\left(\mathrm{W} \mathrm{m}^{-2}\right)$ & $-1.1(-1.7)$ & $-2.3(-3.6)$ \\
Low cloud cover $(\%)$ & $-2.3(-0.7)$ & $-2.1(-0.3)$ \\
Middle cloud cover $(\%)$ & $-2.5(-1.2)$ & $-2.9(-0.8)$ \\
High cloud cover $(\%)$ & $-0.4(-0.8)$ & $-1.0(-1.5)$ \\
Total cloud cover $(\%)$ & $-2.1(-1.2)$ & $-2.5(-1.5)$ \\
Convective precipitation $\left(\mathrm{mm} \mathrm{day}^{-1}\right)$ & $0.2(0.1)$ & $0.2(0.2)$ \\
Stable precipitation $\left(\mathrm{mm} \mathrm{day}^{-1}\right)$ & $0.0(0.0)$ & $0.1(0.1)$ \\
Total precipitation $\left(\mathrm{mm} \mathrm{day}^{-1}\right)$ & $0.2(0.2)$ & $0.3(0.3)$ \\
Cloud liquid water path $\left(\mathrm{g} \mathrm{m}^{-2}\right)$ & $-1.3(-0.4)$ & $-2.5(-6.7)$ \\
Cloud ice water path $\left(\mathrm{g} \mathrm{m}^{-2}\right)$ & $-1.5(-0.5)$ & $-3.2(-2.6)$ \\
\hline
\end{tabular}

respectively. The relative reductions in vertically integrated cloud liquid and ice in each IRIS simulation dominate over the reduction in horizontal cloud cover. In other words, the imposed iris feedback appears to predominantly yield cloud thinning or reduced cloud albedo, while the cloud fraction reductions are more subtle. The influence of CRE on surface temperature can be seen more clearly in a radiatively forced setting, discussed in section 6 .

As the efficiency of convective precipitation is increased in IRIS10, cloud albedo and the associated cooling effect reduces, causing warming in the tropics. Consequently, the Hadley cell, depicted by the zonalmean, annual-mean meridional streamfunction $\psi$ in Fig. 3, is expected to weaken (e.g., Lu et al. 2007). A weaker northern branch of the Hadley circulation is prominent in IRIS10, where the difference in $\psi$ between IRIS10 and CESM $\Delta \psi$ is negative (clockwise circulation) and opposes $\psi$. The weakening signal is also evident for the southern branch with a more complex vertical structure, but is the same sign and slightly weaker than that in the Northern Hemisphere. In the tropics, the latent heat release through precipitation is balanced by longwave radiative cooling. Radiative cooling rates in the atmosphere increase moderately with warming, at $\sim 1.5 \%$ as compared with the $7 \%$ increase in water vapor per kelvin. Consequently, the large-scale circulation must slow down as limited by the radiative cooling rate in order to maintain the balance (Soden and Held 2006). In the IRIS experiments, higher $C_{p}$ effectively warms the surface by reducing the magnitude of SW CRE, which is consistent with weakening of the Hadley circulation by the above thermodynamic argument.

\section{Comparison with observations}

We investigate the radiative effects of high-level clouds in the tropical Pacific using monthly cloud fraction and radiative fluxes from satellite-derived observations. High cloud fraction (HCF) is estimated from the Terra Moderate Resolution Imaging Spectroradiometer (MODIS) by the National Aeronautics and Space Administration (NASA), following Choi et al. (2017). MODIS cloud fraction based on $1.38-\mu \mathrm{m}$ reflectivity and optical depth greater than $\sim 0.1$ were used

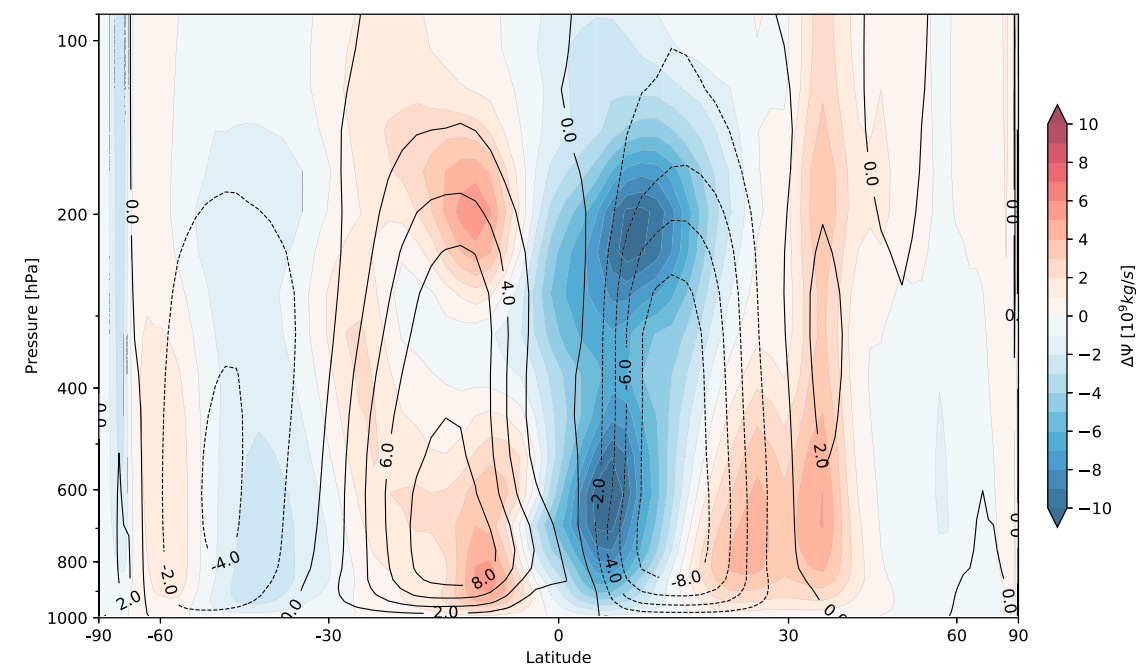

FIG. 3. Zonal-mean, annual-mean mass streamfunction ( $\psi$; contour lines) in CESM, and the difference $\Delta \psi$ between IRIS10 and CESM (IRIS10 minus CESM; color bar). The units of $\psi$ and $\Delta \psi$ are $10^{10}$ and $10^{9} \mathrm{~kg} \mathrm{~s}^{-1}$, respectively. In IRIS10, the ascending branch of the Hadley circulation is weaker in both hemispheres relative to CESM. 

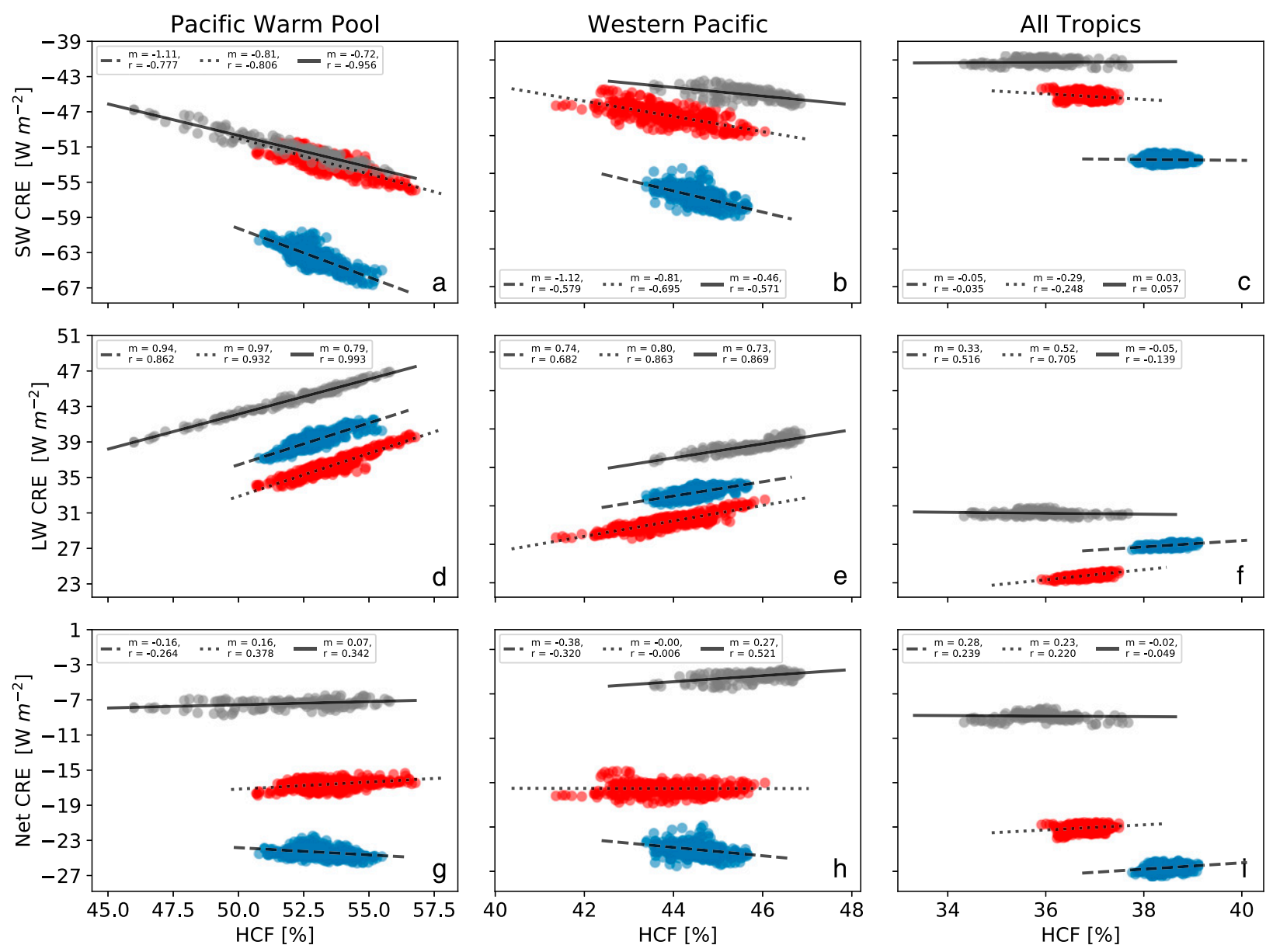

FIG. 4. (a)-(c) SW CRE, (d)-(f) LW CRE, and (g)-(i) net CRE (SW + LW) against HCF from A-Train satellite-derived observations (gray), CESM (blue), and IRIS10 (red). The seasonal cycle of insolation is removed by computing a 12-month running mean. The slope and correlation coefficient for each regression line are indicated by $m$ and $r$, respectively. Each data point represents a monthly mean. Monthly observations of HCF from March 2000 to October 2014 are replotted with permission from Choi et al. (2017). Plots (a)-(c) suggest that the simulated anvil clouds in CESM are too bright relative to observations. The SW CRE and LW CRE are similar in magnitude, where they largely cancel out and imply that changes in HCF would only lead to small changes in net CRE.

(Choi et al. 2005). Radiative fluxes at the TOA are from the 4.0 edition of the Energy Balanced and Filled (EBAF-TOA) product of the Cloud and the Earth's Radiant Energy System (CERES) by NASA (data available at https://ceres.larc.nasa.gov/products.php? product $=$ EBAF-TOA; Loeb et al. 2018). The ISCCP cloud-cover histograms used were monthly averages of the ISCCP D1 observations from Pincus et al. (2012), produced to be consistent with the COSP for model evaluation (data available at http://climserv.ipsl. polytechnique.fr/cfmip-obs.html).

Deep convective clouds take preference for the warmest local SST, which are generally found within the Pacific warm pool (PWP; $\left.130^{\circ} \mathrm{E}-170^{\circ} \mathrm{W}, 20^{\circ} \mathrm{S}-20^{\circ} \mathrm{N}\right)$. Consequently, cirrus cloud fraction is known to be highest in the PWP. However, observed cirrus cloud behavior is sensitive to the choice of domain analyzed. Here, the PWP is extended to all of the western Pacific $\left(120^{\circ} \mathrm{E}-155^{\circ} \mathrm{W}, 30^{\circ} \mathrm{S}-30^{\circ} \mathrm{N}\right.$; Choi and Ho 2006$)$, to cover cloud clustering intrusions out of the PWP region and capture the entire fraction of anvil cirrus (Choi et al. 2017). Clouds over the western Pacific have been found to react quickly to surface temperature changes (Wall et al. 2018), defining a region that has been the focus of numerous studies of cloud feedbacks (e.g., Kubar et al. 2011; Behrangi et al. 2012).

Figures $4 a-c$ show the shortwave CRE plotted against HCF with the seasonal cycle of insolation removed for satellite observations and the CESM and IRIS10 simulations. High clouds have a substantial cooling effect in the western Pacific and PWP, where in the latter a $1 \%$ increase in cloud cover is equivalent to $0.72-1.11 \mathrm{~W} \mathrm{~m}^{-2}$ 

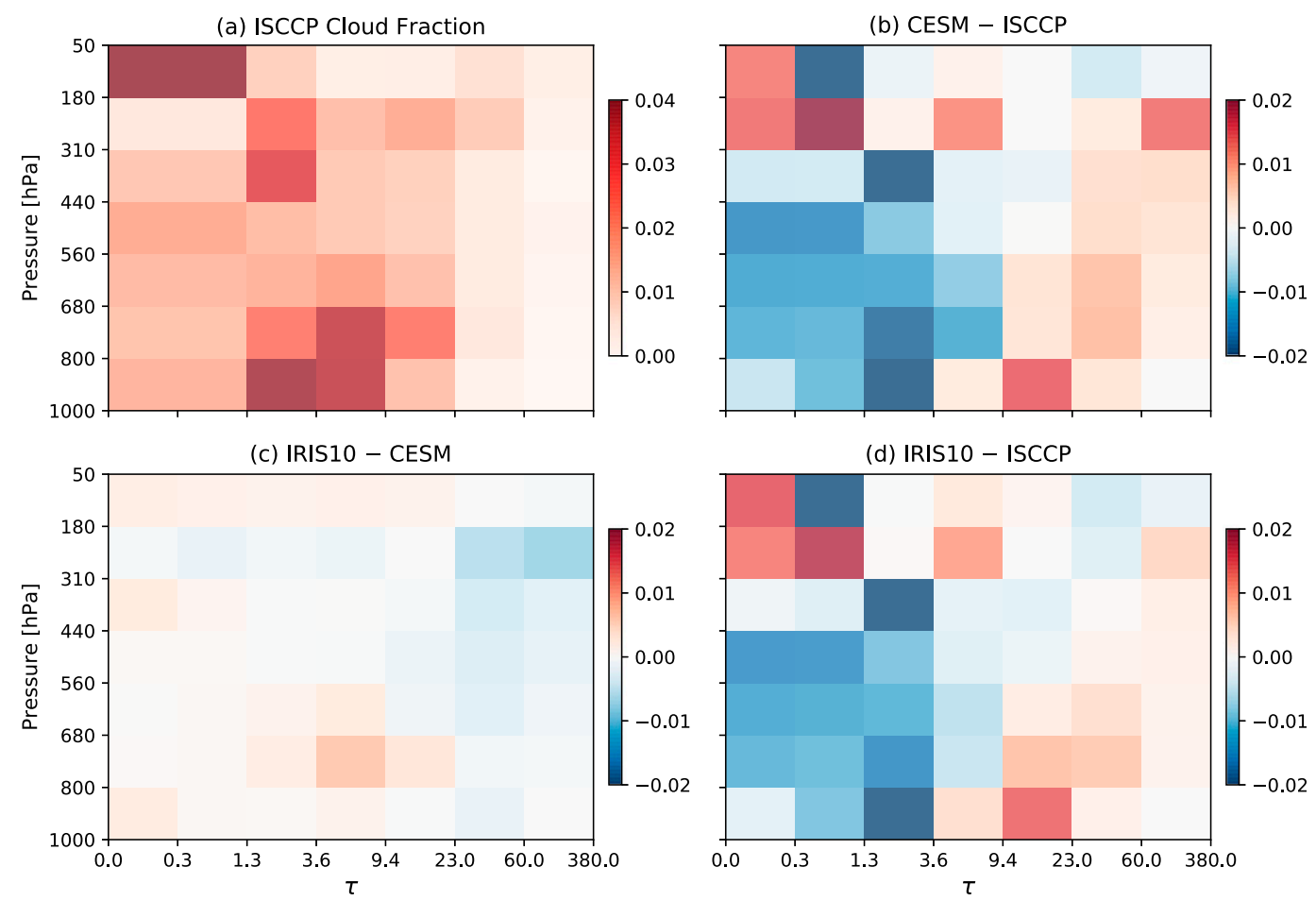

FIG. 5. Observed and simulated annual-mean cloud cover averaged over the $30^{\circ} \mathrm{S}-30^{\circ} \mathrm{N}$ region for (a) ISCCP gridded cloud product from 1983 to 2008, (b) CESM minus ISCCP, (c) IRIS10 minus CESM, and (d) IRIS10 minus ISCCP.

more reflected insolation. Notably, CESM (blue) exaggerates the cooling effect of high clouds in all three regions by over $10 \mathrm{~W} \mathrm{~m}^{-2}$ in the convectively active PWP (Fig. 4a) and western Pacific (Fig. 4b), but nevertheless produces a slope comparable to the observations. The range of SW CRE in IRIS10 (red) are closer to observations and within $4 \mathrm{~W} \mathrm{~m}^{-2}$ over all of the tropics. Interestingly, differences in high-level cloud cover between CESM and IRIS10 in the PWP are indistinguishable. Over the entire tropics, there is $1 \%-2 \%$ less high cloud coverage in IRIS10 than in CESM, which is again more consistent with observations (Fig. 4c). The HCF and biases in SW CRE in CESM are overall improved in IRIS10. The increased precipitation efficiency in IRIS10 reduces the opacity of the detrained high clouds from convection, resulting in lower cloud albedo (or lower magnitude of shortwave CRE).

Cirrus clouds exert a strong LW effect on the radiation budget owing to their high altitude and thus low cloud-top temperature. For this reason, LW CRE is observed to be tightly correlated with the area-weighted high-level cloud fraction (Fig. 4, gray). Quantitatively, observations show that a $1 \%$ reduction in HCF would lead to $\sim 0.8 \mathrm{~W} \mathrm{~m}^{-2}$ less longwave CRE in the PWP (Fig. 4d). Notably, the simulated slopes in CESM again resemble that in the observations, while the LW warming effects of these clouds are systematically underestimated by $\sim 4 \mathrm{~W} \mathrm{~m}^{-2}$. In IRIS10, clouds are thinner, where the longwave CRE is systematically lower than that in CESM by $\sim 3 \mathrm{~W} \mathrm{~m}^{-2}$ (Figs. $4 \mathrm{~d}-\mathrm{f}$ ). While biases exist in the simulated SW and LW radiative effects of tropical high clouds, the slopes in Fig. 4 are in general agreement with observations.

A comparison of cloud fraction at each optical depth $\tau$ and cloud top pressure between the observations, CESM, and IRIS10 is shown in Fig. 5. In combination with Fig. 4, there is, in general, an excess of optically thick clouds $(\tau \geq 9.4)$ and a deficiency of the optically thinner clouds $(\tau \leq 3.6)$ simulated by standard CESM (Fig. 5b). These biases lead to the magnitude of shortwave CRE being too large in CESM, as CAM simulates too many thick anvils and not enough medium-thin anvils (Wall and Hartmann 2018). Relative to CESM, the thick cloud bias is improved in IRIS10, especially for the thicker clouds ( $\tau \geq 3.6$ ) with cloud-top pressures (CTPs) that lie between 310 and $180 \mathrm{hPa}$ (Fig. 5c), which is associated with an $\sim 1 \%$ reduction in cloud fraction in IRIS10 relative to CESM (Fig. 5d). This reduction is negligible for the thinner clouds $(\tau \geq 3.6)$ as the smaller signal can be explained by rising anvil 

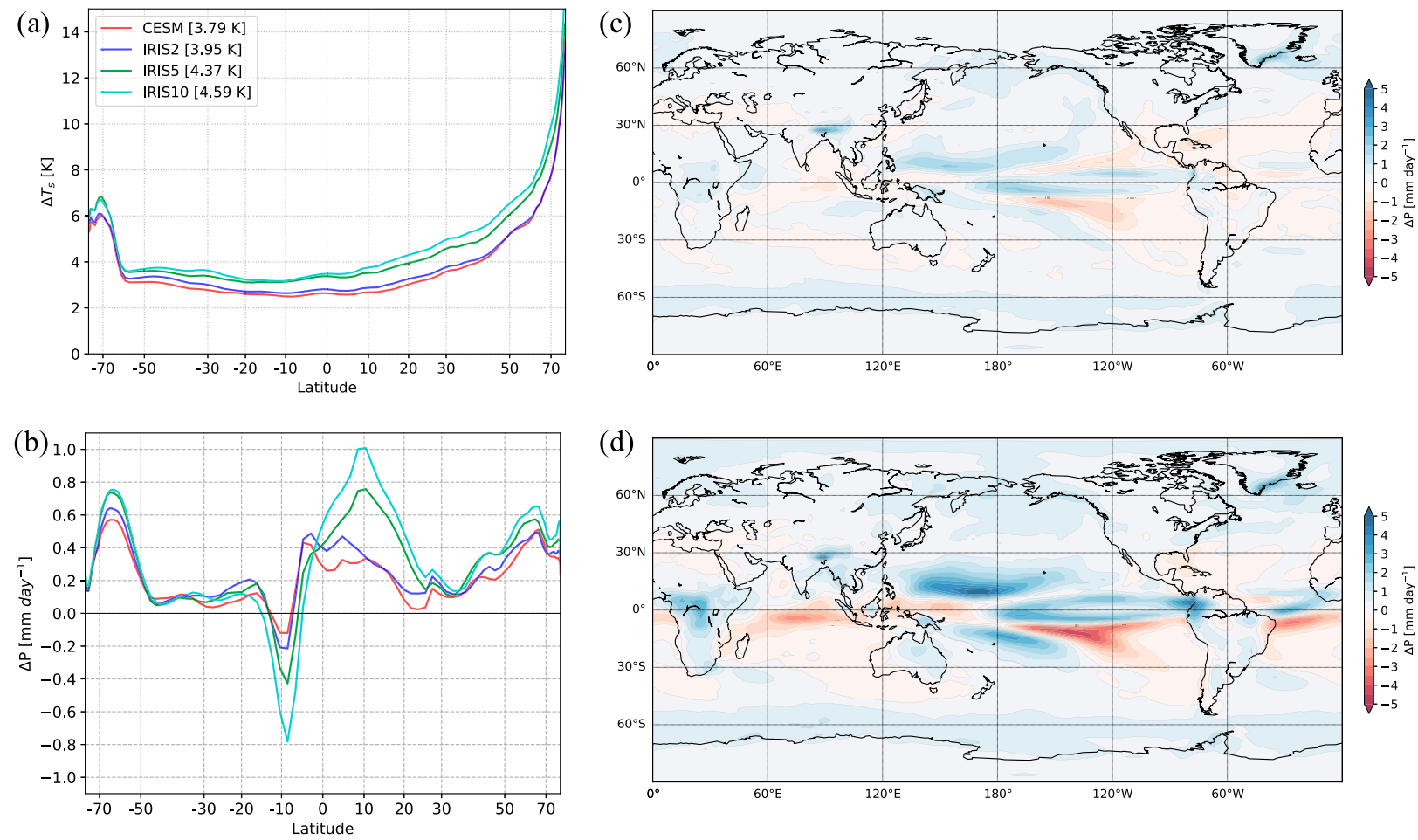

FIG. 6. Zonal-mean (a) surface temperature and (b) precipitation changes per $\mathrm{CO}_{2}$ doubling, defined here as a 30 -yr average of the doubled $\mathrm{CO}_{2}$ simulation minus its preindustrial control, after the model has reached top-of-atmosphere radiation balance. Regional precipitation changes per $\mathrm{CO}_{2}$ doubling in (c) CESM are amplified in (d) IRIS10, showing increases to precipitation after imposing Eq. (1) with $I_{e}=1.0$.

tops due to a warmer surface temperature. For the same reason, the longwave CRE is lowest in IRIS10, as the reduced high clouds now trap less outgoing longwave radiation. Interestingly, there is a dipole-like structure in the bias between CESM and ISCCP (Fig. $5 b)$ for the thin cirrus $(0.3 \leq \tau \leq 1.3 ; 310 \leq \mathrm{CTP} \leq 50)$. The present analysis suggests that the thin cirrus between 310 and $180 \mathrm{hPa}$ in CESM could be too low, which could account for the deficiency in simulating enough greenhouse effect of these clouds in CESM (Figs. 4d-f). However, we note that there are limitations to the ISCCP dataset for the thinnest clouds $(\tau<1.3$; Pincus et al. 2012), which weakens our confidence of the dipolelike bias.

If convective precipitation efficiency increases in a warmer climate, the expectation is that less cloud condensate would be available for upper-level detrainment. Mass flux for cirrus detrainment would be consequently reduced, which would in turn translate into a reduction of horizontal cloud cover (HCF), vertical extent (optical depth), or a combination of the two (Fig. 1). The slope for net CRE (Fig. 4i) provides information on the potential cloud feedback that arises from changes in HCF. The moderate slopes of $\sim 0.2 \mathrm{~W} \mathrm{~m}^{-2}$ or less per $1 \%$ change in HCF show that changes in HCF have a small impact on net CRE, due to their nonnegligible cloud albedo that largely compensates the strong greenhouse effect. However, we note that a small TOA radiative effect does not necessarily imply a negligible climate impact, as anvil clouds are important for the tropical general circulation (e.g., Houze 1982). This CRE cancellation is consistent with the findings by Hartmann and Berry (2017). Thus, changes to the fractional cover of high clouds has a small effect on the net CRE, giving potential implications for the magnitude of the introduced feedback and hence the climate sensitivity to radiative forcing.

\section{Responses to a doubling of atmospheric $\mathrm{CO}_{2}$}

In this section, we investigate the differences between the equilibrated climate for each case after an abrupt doubling of atmospheric $\mathrm{CO}_{2}$. With larger $I_{e}$, the $2 \times \mathrm{CO}_{2}$ simulations equilibrate to increasingly higher mean $T_{s}$ relative to simulations with present-day $\mathrm{CO}_{2}$, but all four simulations yield ECSs within $\sim 1 \mathrm{~K}$ of each other (3.79-4.59 K; Fig. 6a). The surface temperature response is monotonically increased in the tropics as 
well as the extratropics, likely due to polar amplification of the low-latitude warming. There is little change in hydrological sensitivity (global mean precipitation increase per degree of warming) in response to warming between the simulations (not shown). Regionally, the pattern for precipitation responses is similar but amplified in the warmer IRIS10 relative to CESM (Figs. 6c,d), in contrast to what was reported for ECHAM6 simulations with varying $I_{e}$ (MS15). But here we focus on another intriguing difference between MS15 and the present study, namely the sign of the imposed iris feedback.

ECS is inversely proportional to the total feedback parameter, which can be split into linear feedback parameters and their associated mechanisms (Soden and Held 2006). The radiative kernel technique assumes similarity of the radiative transfer calculations across different models (Shell et al. 2008) and has been verified to first order (Soden et al. 2008). Standard global-mean feedback parameters from this calculation technique are shown for each case in Fig. 7. Unsurprisingly, since the imposed change is constructed to operate primarily in the tropics, the feedback associated with glacier/ice sheet retreat $\left(+0.3 \mathrm{~W} \mathrm{~m}^{-2} \mathrm{~K}^{-1}\right)$ is unchanged. With higher $T_{s}$, the amount of water vapor the atmosphere can hold increases exponentially following the ClausiusClapeyron relation, which in turn results in a monotonically stronger water vapor feedback with larger $I_{e}$. The fractional increase in water vapor content is the largest in the upper troposphere, where latent heating relaxes the lapse rate. Lapse rate changes regulate the water vapor feedback by an increased radiative cooling rate in the upper atmosphere. The spread for the combined water vapor and lapse rate feedbacks (from +1.3 to $+1.4 \mathrm{~W} \mathrm{~m}^{-2} \mathrm{~K}^{-1}$ ) is small between each case because the changes in the two feedbacks largely compensate each other (MS15). Thus, because other feedbacks do not contribute substantially to the $0.8-\mathrm{K}$ higher ECS (of IRIS10 relative to CESM), the cloud feedback remains the only explanation for this ECS difference.

The cloud feedback is separated into its LW and SW components (Fig. 7), both being key pieces of the positive feedback. The standard version of CESM, with a positive cloud feedback in both the $\mathrm{LW}\left(0.17 \mathrm{~W} \mathrm{~m}^{-2} \mathrm{~K}^{-1}\right)$ and SW $\left(0.64 \mathrm{~W} \mathrm{~m}^{-2} \mathrm{~K}^{-1}\right)$, lies comfortably within the reported CMIP5 range. A positive SW feedback greater than the CMIP5 multimodel mean $\left(0.37 \mathrm{~W} \mathrm{~m}^{-2} \mathrm{~K}^{-1}\right.$; Zelinka et al. 2012a) positions the 3.8-K ECS on the higher end of the CMIP5 intermodel spread. The SW cloud feedback in the IRIS simulations is larger than CESM by up to $0.5 \mathrm{~W} \mathrm{~m}^{-2} \mathrm{~K}^{-1}$ which, provided other feedbacks are similar, explains the 0.8-K higher ECS. The LW feedback components are unexpectedly similar

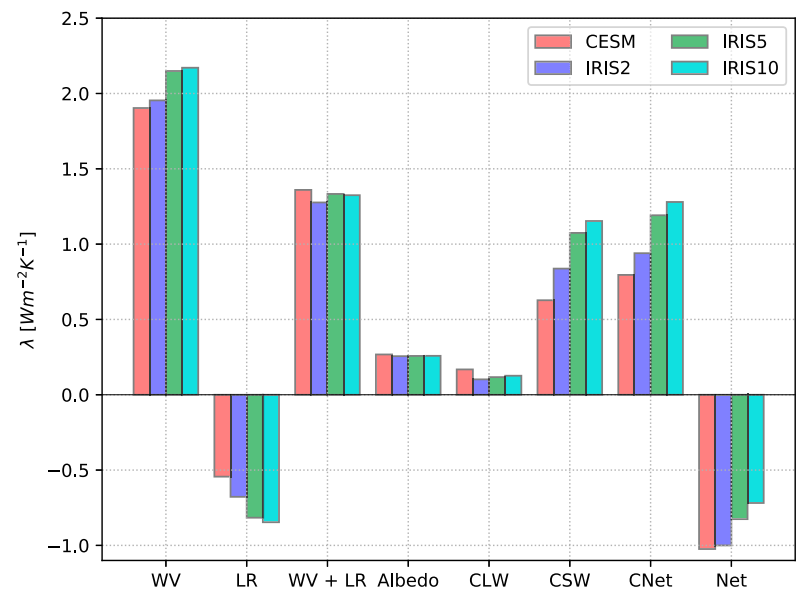

FIG. 7. Climate feedback contributions from water vapor (WV), lapse rate (LR), their sum (WV + LR), albedo (Albedo), LW cloud (CLW), SW cloud (CSW), and total cloud (CNet) feedbacks. Each feedback parameter $\lambda$ is computed offline for each case using the radiative kernel method (Shell et al. 2008). "Net" is the sum of all feedbacks (all shown feedbacks plus the Planck feedback). Net $\lambda$ changes from -1.0 (CESM) to -0.7 (IRIS10) $\mathrm{W} \mathrm{m}^{-2} \mathrm{~K}^{-1}$, corresponding to an $\sim 1-\mathrm{K}$ higher climate sensitivity.

despite evidence for a robust relationship between $\mathrm{HCF}$ and LW CRE (Fig. 4) in the tropics. On one hand, the negative LW cloud feedback associated with the reduction of HCF is largely offset by the SW cloud feedback of opposite sign. But more importantly, the difference in fractional high cloud cover is relatively small ( $\sim 1 \%$ ) between each case (Table 2 ). If changes to $\mathrm{HCF}$ are not large, then the cloud feedback as manifested through changes in the horizontal coverage of high clouds would necessarily also have to be small (see Fig. S3 in the online supplemental material for responses of cloud cover to warming). Furthermore, the IWP in CESM decreases by $0.5 \mathrm{~g} \mathrm{~m}^{-2}$ (3\% relative change) in response to a doubling of atmospheric $\mathrm{CO}_{2}$ (Table 3). The reduction in IWP is amplified significantly in the IRIS10 simulation to $2.6 \mathrm{~g} \mathrm{~m}^{-2}(26 \%$ relative change).

To visualize the reduction in cloud optical depth, we show the cloud fraction changes (normalized by surface temperature) in response to warming over the PWP (Fig. 8). The warming response of high clouds $(440<$ CTP) in CESM (Fig. 8a) is dominated by a reduction between 310 and $180 \mathrm{hPa}$ and an increase between 180 and $50 \mathrm{hPa}$. This dipole-like pattern is largely due to rising cloud tops according to the fixed anvil temperature hypothesis. Thinning of ice clouds is evident from the blue patches between $\tau>9.4$ and $440<$ CTP $<180$ of Fig. 8b, indicating that optically thick cloudiness reduces in IRIS10 in response to warming when compared with CESM. In addition, there is a small increase in 
(a) CESM

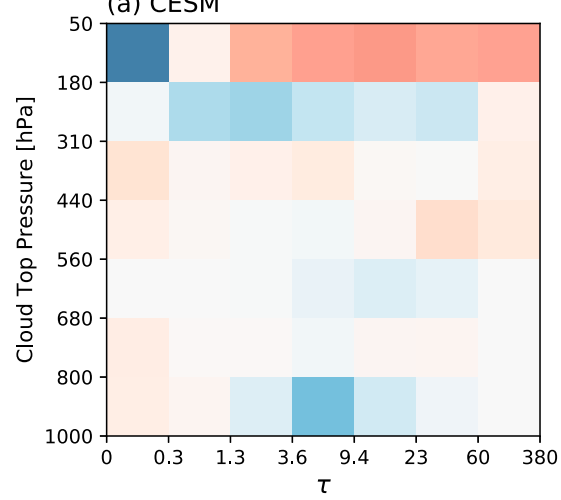

(b) IRIS10

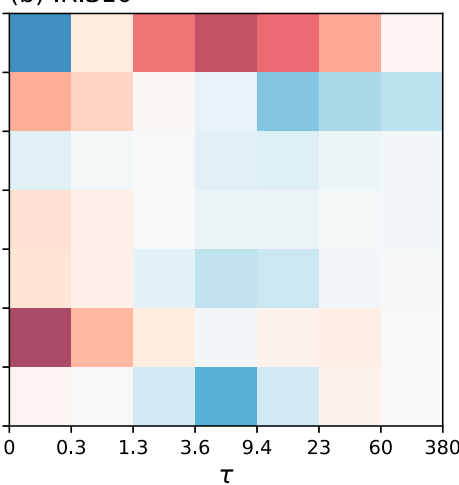

(c) IRIS10 - CESM

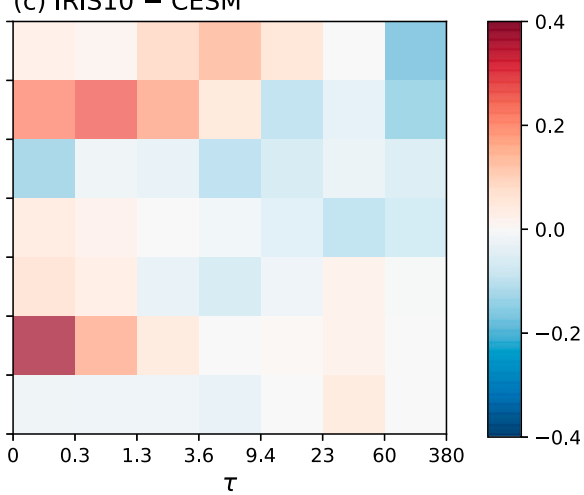

FIG. 8. Cloud-cover warming response $\left(2 \times \mathrm{CO}_{2}\right.$ minus preindustrial) over the PWP region (defined in the text) for (a) CESM, (b) IRIS10, and (c) IRIS10 minus CESM. $\left(\% \mathrm{~K}^{-1}\right)$. Anvil thinning is supported by the reduction of thick cirrus clouds $(\tau>9.4 ; 560<$ CTP $<50)$ in (c).

thinner cloud cover $(\tau<9.4)$ within the same altitude range. This cloud thinning is depicted more clearly in the differences between IRIS10 and CESM (Fig. 8c). The increased magnitude of the positive SW cloud feedback (and hence ECS) from CESM to IRIS10 is attributed to the optical thinning of cirrus clouds (Fig. 1, red arrows). Apart from the aforementioned changes to high clouds, the optically thinnest low cloud fraction $(\tau<1.3)$ between 800 and $680 \mathrm{hPa}$ increases. However, changes to these clouds, being optically thin and low in altitude, have a smaller impact on CRE and cloud feedbacks (not shown).

The cloud feedback can be decomposed into contributions from changes in amount, altitude, and optical depth (Zelinka et al. 2012b). This method computes the cloud feedback at each cloud-top-pressure and opticaldepth bin using a similar radiative kernel technique to that described in Shell et al. (2008). Figure 9 shows the global mean cloud feedback contributions from high (CTP $<440 \mathrm{hPa}$; hatched bars) and all clouds (all CTPs). By construction, the individual feedback components (amount, altitude, and optical depth) for low (CTP > $440 \mathrm{hPa}$ ) and high clouds cannot be summed. Accordingly, we show the feedback decompositions for high and all clouds only. However, isolating contributions from high clouds is useful for distinguishing individual cloud feedbacks that are robustly zero from those that are not (Zelinka et al. 2016), and comparing these components between CESM and IRIS. It is also worth noting that the results shown in Figs. 9-11 differ slightly from that in Fig. 7, but the SW and LW components are expected to be consistent to within $5 \%$ and $15 \%$, respectively (Zelinka et al. 2012a).

The total high cloud feedback in CESM is near neutral $\left(\sim 0.05 \mathrm{~W} \mathrm{~m}^{-2} \mathrm{~K}^{-1}\right.$, Fig. $\left.9 \mathrm{c}\right)$, as a residual of the positive LW ( $\sim 0.45 \mathrm{~W} \mathrm{~m}^{-2} \mathrm{~K}^{-1}$, Fig. 9a) and negative SW cloud feedbacks $\left(\sim 0.4 \mathrm{~W} \mathrm{~m}^{-2} \mathrm{~K}^{-1}\right.$, Fig. $\left.9 \mathrm{~b}\right)$. The amount of feedback due to high clouds in Figs. 9a and 9b agrees with the regression analysis in Fig. 4, as the positive LW feedback associated with a reduced greenhouse effect completely offset by the negative SW feedback associated with reduced cloud albedo. This is also consistent with the close to net neutral CRE found in this study (Fig. 4) and in observed tropical anvil clouds (Hartmann and Berry 2017). The SW optical-depth feedback is negative for CESM due to the cloud phase feedback (e.g., Storelvmo et al. 2015), where ice clouds are replaced by long-lasting and more reflective liquid clouds. This feedback can operate in low, midlevel, and high clouds, depending on the latitude. However, the negative optical-depth feedback is gradually more than compensated by thinning of anvil clouds (Fig. 8b) when an increasingly stronger iris feedback is imposed.

The high-cloud compensation between the LW and SW amount feedbacks is also evident in IRIS simulations (Fig. 9c), with the net amount feedback staying constant. With larger $I_{e}$, the increase in the net high cloud feedback is largely due to a decrease in the magnitude of the negative SW feedback. The latter trend is attributed to the aforementioned reduction in IWP and LWP. The greenhouse effect has only a weak dependence on the optical depth, because most clouds, except optically very thin ones (e.g., in the ISCCP cirrus category where $\tau \leq 3.6$ ), will have an emissivity close to unity (Fu and Liou 1993). Thus, the difference in highcloud LW optical-depth feedbacks between CESM and IRIS simulations is within $0.05 \mathrm{~W} \mathrm{~m}^{-2} \mathrm{~K}^{-1}$. Without significant LW compensation, optical thinning of anvil clouds increases the net cloud-optical-depth feedback (Fig. 9c), from $0.09 \mathrm{~W} \mathrm{~m}^{-2} \mathrm{~K}^{-1}$ (CESM) to $0.38 \mathrm{~W} \mathrm{~m}^{-2} \mathrm{~K}^{-1}$ (IRIS10). This is in large part due to anvil thinning, which is responsible for the reversed iris feedback, as optically thinner clouds reflect less insolation. The coupling between SW and LW CRE hinders the climate 


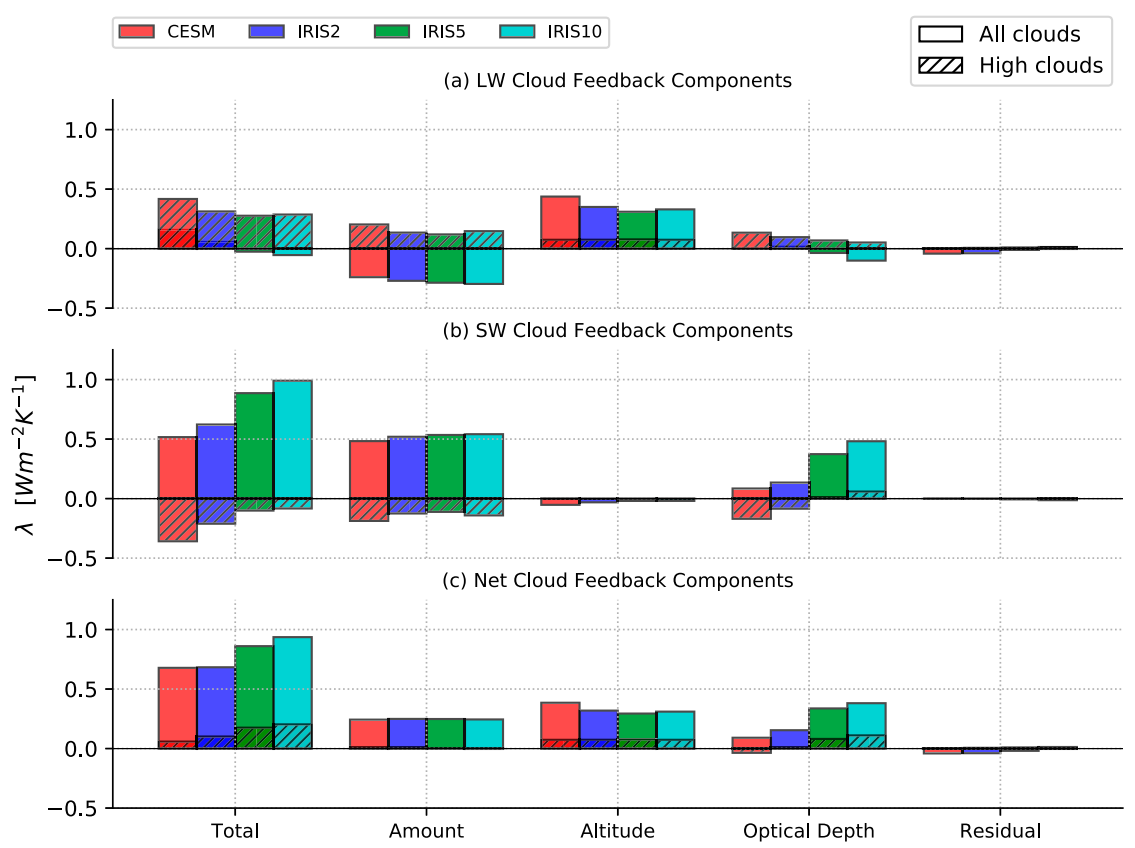

FIG. 9. Global mean cloud feedback contributions separated into cloud-amount, cloudaltitude, and cloud-optical-depth components computed from cloud fraction histograms with cloud-optical-depth and cloud-top-pressure bins. A separate decomposition is performed for high clouds $(<440 \mathrm{hPa})$, shown with hatched bars. Note that these high-cloud components are only useful for magnitude comparison because they are not additive with low-cloud (i.e., $>440 \mathrm{hPa}$, not shown) components to give back the all-cloud components (all pressure bins). The SW high-cloud-optical-depth feedback increases when the iris parameter $I_{e}$ is increased, leading to a larger net cloud feedback in IRIS10 than in CESM.

system to exert a strong negative feedback, as the net radiative effects from high-level cloudiness is effectively neutral. However, a strong positive cloud feedback associated with Eq. (1) is possible so long as the reduced convective detrainment, in addition to horizontal coverage, reduces anvil optical depth. The latter increases the magnitude of the positive SW optical-depth feedback and has a much smaller effect in the LW, increasing the magnitude of the net cloud feedback to more positive values.

The spatial cloud feedback distributions in standard CESM (Fig. 10) agree with the CMIP5 cloud feedbacks estimated using the same radiative kernels across 11 models (Zelinka et al. 2012b). The net cloud feedback in CESM is positive in the extratropics but remains close to neutral over the tropics (Fig. 10, top right panel). The change in the cloud-optical-depth feedback in the IRIS10 simulation (Fig. 11) is primarily located over the tropical Pacific, where it changes sign over the central Pacific. There are also similar changes over tropical land areas such as South America and sub-Saharan Africa. Notably, the change from negative to positive opticaldepth feedback in the western Pacific and over the southern Indian Ocean is consistent with anvil thinning
(Fig. 1). Cloud feedbacks related to changes in horizontal extent (amount; $0.24 \mathrm{~W} \mathrm{~m}^{-2} \mathrm{~K}^{-1}$ ) and altitude $\left(0.31-0.38 \mathrm{~W} \mathrm{~m}^{-2} \mathrm{~K}^{-1}\right)$ are similar between the CESM and IRIS10 simulations and spatially coherent. In all IRIS simulations, the imposed reduction in detrained cloud water or ice with warming mainly results in a thinning of high clouds, as opposed to the inferred neutral or low-magnitude response from reducing their horizontal coverage.

\section{Sensitivity to cloud macrophysics}

In this section, we explore the robustness of the cloud thinning dominance in CESM across three alternative ice cloud macrophysics schemes that vary in their calculation of in-grid cloud fraction from prognostic variables such as in-cloud ice water content, super saturation, and the large-scale humidity and temperature. The rationale for these sensitivity tests was that different dependence of ice cloud cover on the above variables would likely affect the partitioning between cloud thinning and cloud cover retreat in response to warming. The macrophysics schemes determine the diagnostic ice cloud fraction from the model-resolved variable fields. 
(a) LW Total (0.16)

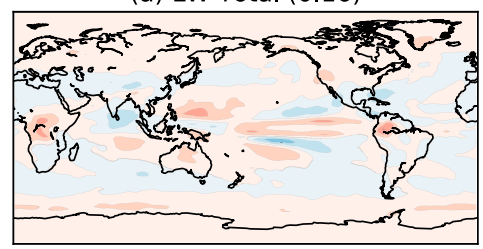

(d) LW Amount (-0.24)

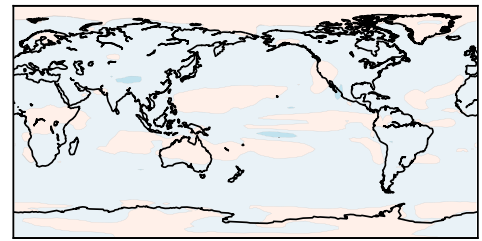

(g) LW Altitude (0.44)

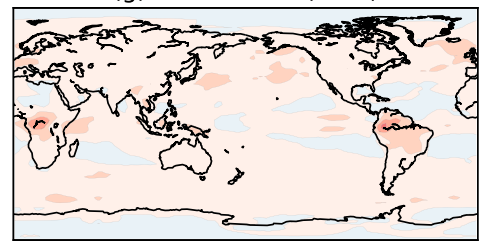

(j) LW Optical Depth (0.01)

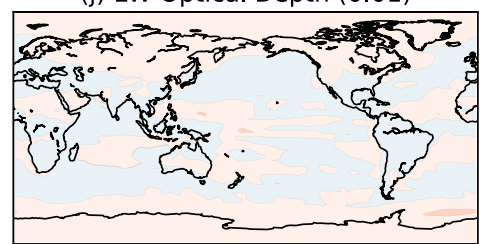

(b) SW Total (0.52)

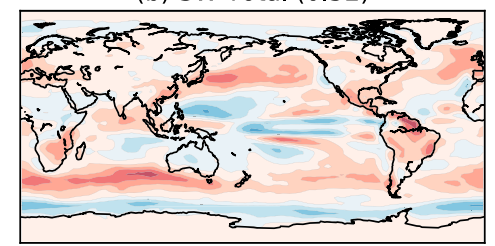

(e) SW Amount $(0.48)$

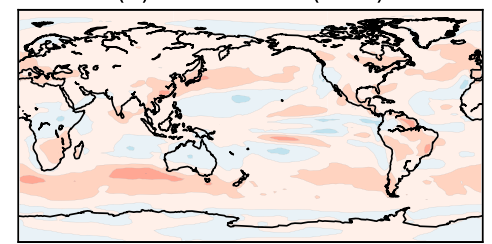

(h) SW Altitude (-0.05)

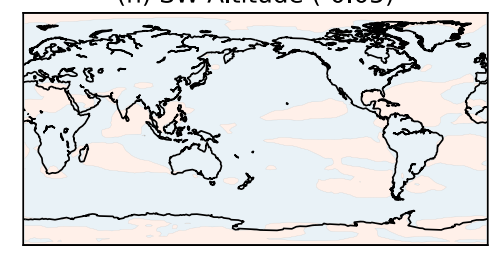

(k) SW Optical Depth (0.08)

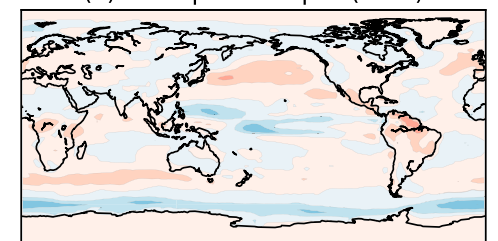

(c) Net Total (0.68)

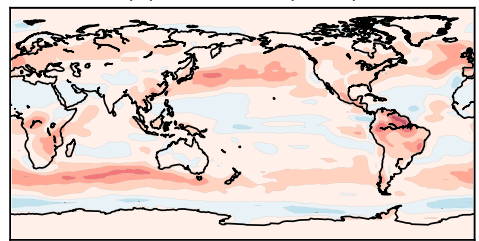

(f) Net Amount (0.24)

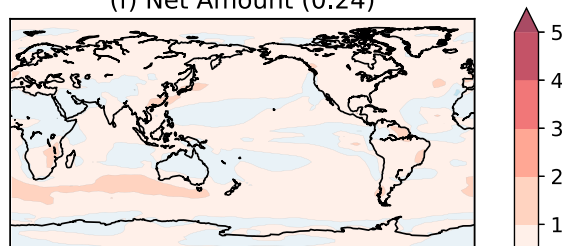

(i) Net Altitude (0.38)

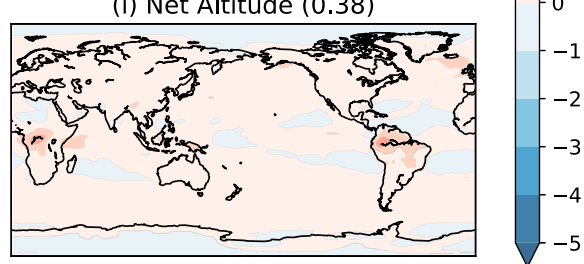

(I) Net Optical Depth (0.09)

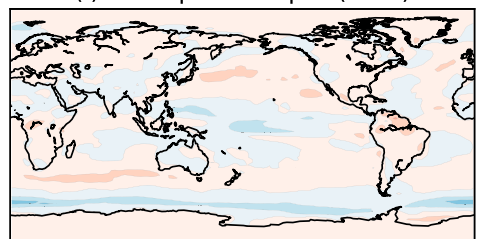

FIG. 10. Spatial distribution of LW, SW, and net cloud feedback contributions due to changes in amount, altitude, and optical depth for the CESM simulation. Global mean values $\left(\mathrm{W} \mathrm{m}^{-2} \mathrm{~K}^{-1}\right)$ are shown in the parentheses of each panel.

Ice and liquid can coexist in the same grid, but are handled separately (Gettelman et al. 2010), and total gridbox cloud fraction is calculated assuming maximum overlap between liquid and ice clouds. The Schiller et al. (2008) scheme (hereinafter ICE2) determines ice fraction based on a ratio between the in-cloud ice water content and its empirical temperature-dependent value. Wood and Field's (2000) scheme (hereinafter ICE3) bases ice cloud fraction only on background relative humidity. The Wilson and Ballard (1999) scheme (hereinafter ICE4) takes into account the vapor, incloud liquid and ice, and the background air temperature. Variability is large across the aforementioned ice schemes (Gettelman et al. 2010), providing suitable cases for comparison.

Table 4 compares simulations for each ice scheme for both the strongest iris feedback $\left(I_{e}=1.0\right)$ case and its $I_{e}=0$ counterpart under preindustrial $\mathrm{CO}_{2}$. The ICE2 scheme has much less horizontal cloud cover at all levels relative to the default scheme, with $\sim 18 \%$ less high cloud and $\sim 10 \%$ less total cloud cover. The global and tropical mean precipitation is similar. There is also vertical thinning of liquid clouds $(\sim 5 \%$ relative reduction in LWP) and ice clouds ( $\sim 13 \%$ relative reduction in IWP) in ICE2 relative to CESM. The result of a combination of these effects is that the net CRE decreases and the simulated climate in ICE2 is cooler (by $\sim 1.5 \mathrm{~K}$ ) than CESM. Going from the default ice scheme to the ICE3 and ICE4 schemes, the arguments are similar, the main difference being that the reduction in high cloud cover and thus the surface temperature is not as strong. Overall, the mean climate is not considerably altered in terms of the precipitation and the CRE on the global radiation balance. Previously, we noted that increased precipitation efficiency led to a subtle change in horizontal cloud coverage and a stronger reduction in vertically integrated cloud liquid and ice. The reductions in LWP and IWP also dominate across various macrophysics schemes. Differences between the standard and iris-like climates among the ice schemes are strikingly similar, and also similar between CESM and IRIS10. In all cases, the larger decrease in IWP (17\% - $20 \%$ relative reduction) dominates over the smaller retreat in horizontal high cloud coverage 
(a) LW Total $(-0.05)$

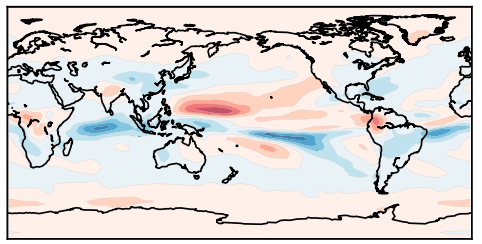

(d) LW Amount (-0.30)

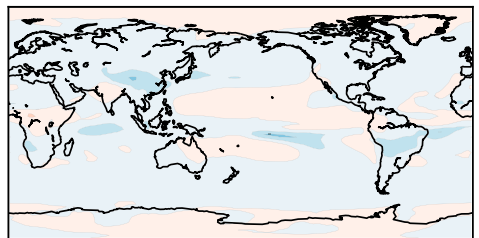

(g) LW Altitude (0.33)

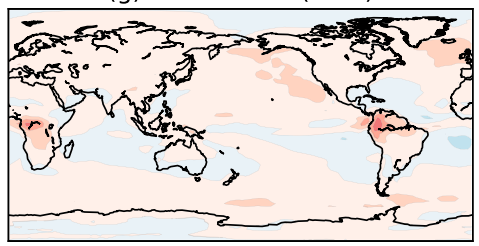

(j) LW Optical Depth (-0.10)

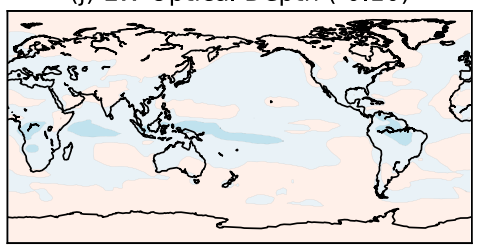

(b) SW Total (0.99)

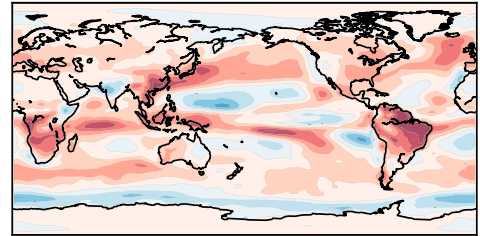

(e) SW Amount (0.54)

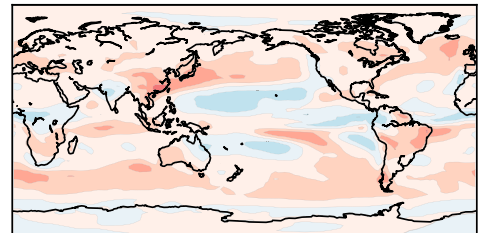

(h) SW Altitude (-0.02)

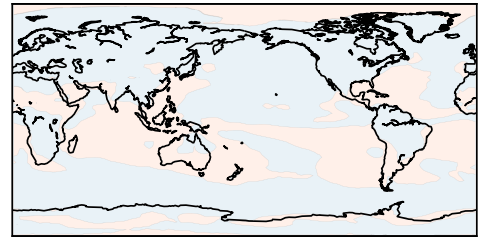

(k) SW Optical Depth (0.48)

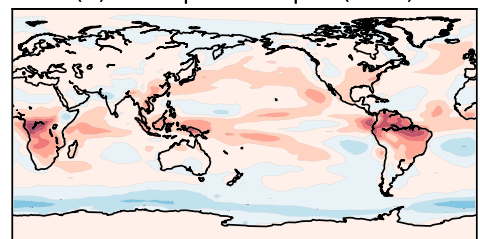

(c) Net Total (0.94)

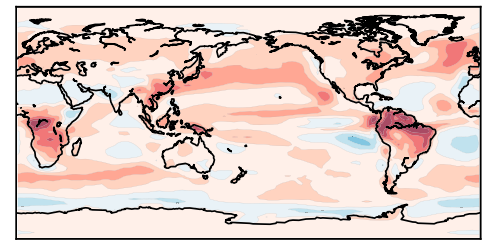

(f) Net Amount (0.24)

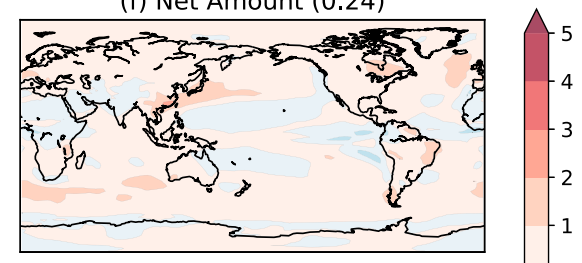

(i) Net Altitude (0.31)

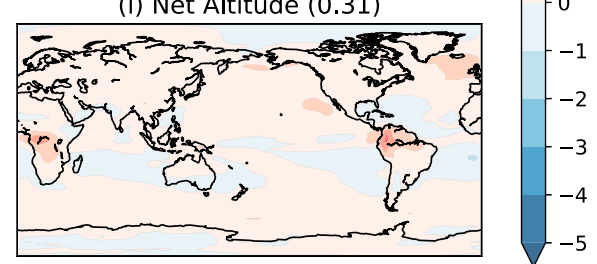

(I) Net Optical Depth $(0.38)$

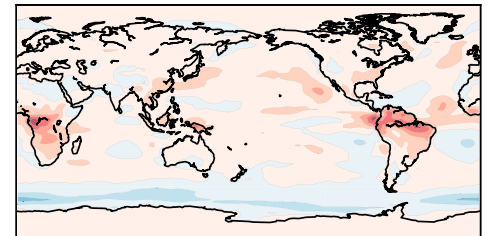

FIG. 11. As in Fig. 10, but for the IRIS10 simulation. The net optical-depth feedback is much larger relative to CESM, as a result of the SW optical-depth feedback changing from negative to positive (e.g., over the western Pacific and Indian Ocean).

$(<3 \%)$. If this pattern persists when the climate warms in response to doubled atmospheric $\mathrm{CO}_{2}$ concentrations, so will the positive cloud feedback due to a cloudoptical-depth feedback.

Figure 12 illustrates the cloud feedback contributions associated with the eight simulations in Table 4, which are ordered to facilitate comparison across the different ice schemes under the same $C_{p}$. The introduced feedback through Eq. (1) is robustly positive across all ice schemes, which increases the ECS. The longwave cloud amount feedback reduces in magnitude from ICE2 to ICE2-IRIS10 the greatest among all schemes. However, the magnitude remains small $\left(<0.2 \mathrm{~W} \mathrm{~m}^{-2} \mathrm{~K}^{-1}\right)$ and is still veiled by the strong change in the SW cloud feedback, giving an increase in magnitude of the net cloud feedback of about $+0.5 \mathrm{~W} \mathrm{~m}^{-2} \mathrm{~K}^{-1}$. While this increase of the net cloud feedback varies among the ice schemes $\left(\sim 0.5-0.7 \mathrm{~W} \mathrm{~m}^{-2} \mathrm{~K}^{-1}\right)$, the sign is robust and positive in this model, because none of the cloud macrophysics schemes that were tested yield changes to the horizontal coverage of high clouds large enough to dominate over the corresponding optical-depth changes. As the result of $I_{e}=1.0$, clouds become optically thinner with warming (Fig. 12b), where the optical-depth feedback changes from neutral to positive. The effect of the vertical thinning is evident here. In each alternative ice scheme, despite having significantly altered mean state cloud cover, vertical cloud thinning dominates over cloud-cover changes for a distinctly positive cloud radiative feedback (Fig. 1, red arrows).

\section{Conclusions}

A series of simulations using CESM, with CAM5.3 physics coupled to a slab ocean, have been used to explore the climate impact of a potential reduction in tropical high clouds as a climate feedback that may arise in nature from warming-induced cloud clustering. By using a simple parameterization to represent this conceivable effect that is currently not represented in GCMs, it was shown that the simulated mean climate became warmer as a result of optically thinner clouds that reflected less insolation. A weakening of the Hadley circulation accompanied the warmer surface 


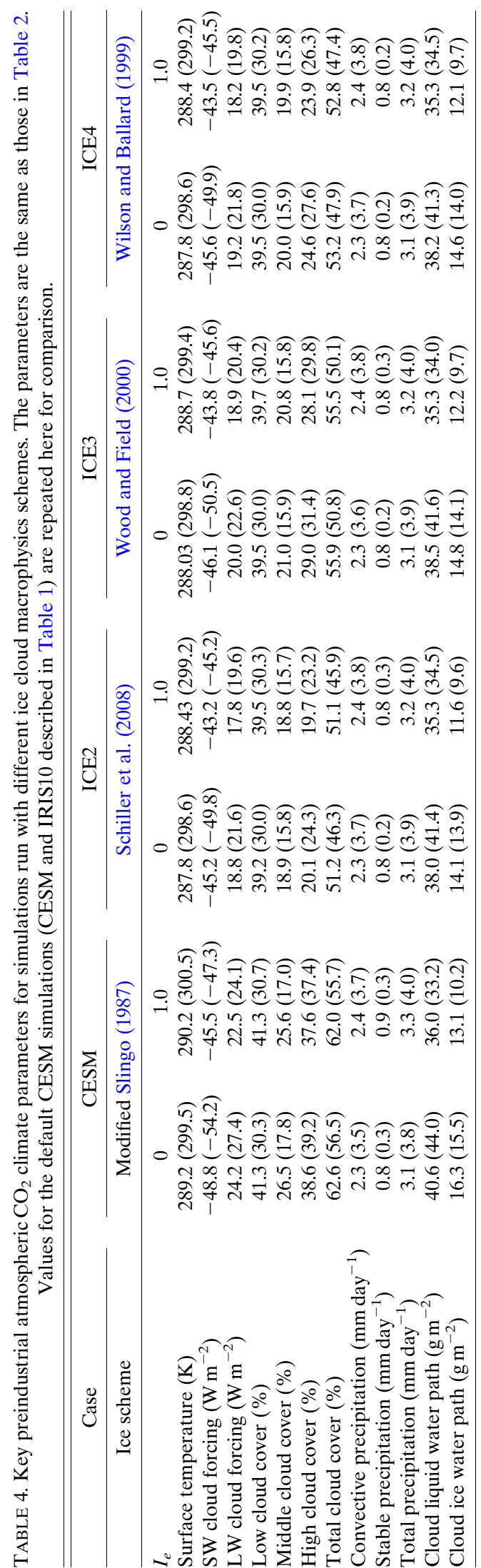




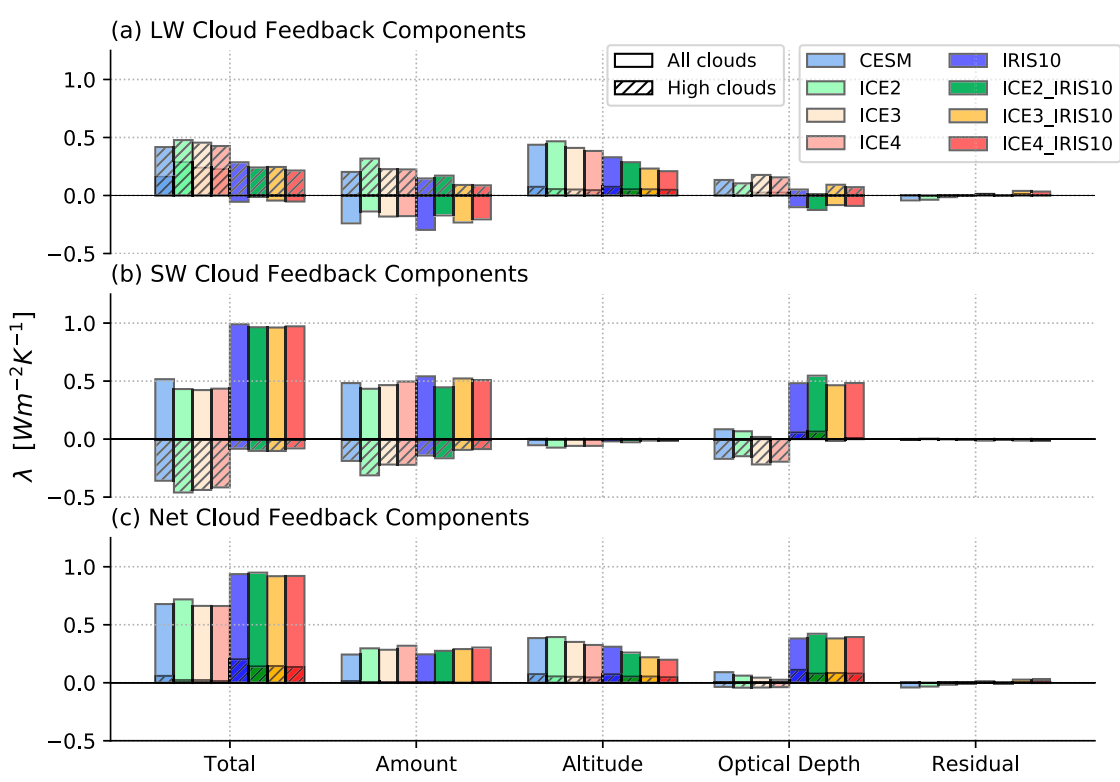

FIG. 12. Cloud feedback decomposition, as in Fig. 9, for each case in Table 4. The IRIS10 suffix refers to the corresponding iris case (with $I_{e}=1.0$ ). The change in optical-depth feedback from $\sim 0$ to $\sim 0.5 \mathrm{~W} \mathrm{~m}^{-2}$, primarily responsible for a higher magnitude net cloud feedback [(c); total], is similar across each ice macrophysics scheme.

temperatures, due to a thermodynamic effect that is generally consistent with current CMIP5 greenhouse warming simulations. In contrast to $\mathrm{MS} 15$, in $\mathrm{CO}_{2-}$ doubling experiments, each simulation with increased convective precipitation efficiency showed a higher equilibrium climate sensitivity. The latter is due to a positive cloud radiative feedback, owing to optical thinning of ice clouds that reduced their albedo without having a significant impact on their greenhouse effect (Fig. 1, red arrows). The feedback associated with optical thinning is robust in the current (Zhang and McFarlane 1995) convection scheme across different cloud macrophysics schemes that lead to different partitioning between reductions in cloud albedo and extent.

Comparing model characteristics with satellitederived observations suggests that the tropical cirrus clouds in CESM reflected an excessive amount of insolation while not trapping enough outgoing longwave radiation. Nevertheless, the simulated change in SW and LW CRE for a given change in high cloud cover is consistent with observations, suggesting that CESM is in fact capable of capturing the radiative response to a reduction in anvil cloud cover. With larger convective precipitation efficiency, the detrained convective mass flux that feeds anvil clouds is reduced as more of the condensate in the updraft is converted into precipitation. As a result, especially in the IRIS10 simulation, the model shortwave bias is improved significantly at the expense of a stronger longwave bias, which originates from the deficiency of the highest and thinnest cirrus clouds. Furthermore, the observed net radiative effects of ice clouds are relatively neutral, as the shortwave and longwave radiative effects largely cancel out. During cloud retreat, the nontrivial albedo effects of ice clouds thus effectively resist the negative longwave iris feedback and constrains the magnitude of the negative feedback.

Although the representation of convective aggregation provided by Eq. (1) is an oversimplification of a highly complex mechanism, it serves as a useful method for a first demonstration of the aftereffects. Our results, together with MS15, have shown that the sign of the feedback produced by this representation is highly model dependent. The results here also indicate that the cloud amount feedback associated with reduced detrained ice content that form anvil cirrus is not necessarily negative, and even if so, is likely small in magnitude. This is a consequence of the net radiative effect of tropical anvil clouds, which is found to be close to neutral here, broadly consistent with previous observational studies (e.g., Choi et al. 2017; Hartmann and Berry 2017). On the other hand, optical thinning of these clouds with warming could produce a robustly positive feedback, as found here. To constrain the importance of this feedback, we recommend follow-up research in the form of a multimodel intercomparison combined with analysis of 
satellite observations that can shed light on how anvil cloud optical depth will change with warming.

Acknowledgments. This work was funded by the National Science Foundation through Grant 1352417 and the European Research Council through Grant 758005. Federov acknowledges support from NSF through Grant AGS-0163807 and from NASA Grant NNX17AH21G, and Choi was supported by the Basic Science Research Program through the National Research Foundation of Korea (NRF) funded by the Ministry of Education (Grant 2018R1A6A1A08025520). We acknowledge computational support from the Yale University Faculty of Arts and Sciences High Performance Computing Facility. We also thank three anonymous reviewers for their helpful comments and suggestions.

\section{REFERENCES}

Allan, R. P., 2011: Combining satellite data and models to estimate cloud radiative effect at the surface and in the atmosphere. Meteor. Appl., 18, 324-333, https://doi.org/10.1002/ met.285.

Behrangi, A., T. Kubar, and B. Lambrigtsen, 2012: Phenomenological description of tropical clouds using CloudSat cloud classification. Mon. Wea. Rev., 140, 3235-3249, https://doi.org/ 10.1175/MWR-D-11-00247.1.

Bodas-Salcedo, A., and Coauthors, 2011: COSP: Satellite simulation software for model assessment. Bull. Amer. Meteor. Soc., 92, 1023-1043, https://doi.org/10.1175/2011BAMS2856.1.

Bony, S., and Coauthors, 2015: Clouds, circulation and climate sensitivity. Nat. Geosci., 8, 261-268, https://doi.org/10.1038/ ngeo2398.

- B. Stevens, D. Coppin, T. Becker, K. A. Reed, A. Voigt, and B. Medeiros, 2016: Thermodynamic control of anvil cloud amount. Proc. Natl. Acad. Sci. USA, 113, 8927-8932, https:// doi.org/10.1073/pnas.1601472113.

Boucher, O., and Coauthors, 2013: Clouds and aerosols. Climate Change 2013: The Physical Science Basis, T. F. Stocker et al., Eds., Cambridge University Press, 571-657, https://doi.org/10.1017/CBO9781107415324.016.

Bretherton, C. S., 2015: Insights into low-latitude cloud feedbacks from high-resolution models. Philos. Trans. Roy. Soc. London, 373A, 20140415, https://doi.org/10.1098/rsta.2014.0415.

Ceppi, P., F. Brient, M. D. Zelinka, and D. L. Hartmann, 2017: Cloud feedback mechanisms and their representation in global climate models. Wiley Interdiscip. Rev.: Climate Change, 8, e465, https://doi.org/10.1002/WCC.465.

Charney, J. G., and Coauthors, 1979: Carbon Dioxide and Climate: A Scientific Assessment. National Academies Press, 34 pp., https://doi.org/10.17226/12181.

Choi, Y.-S., and C.-H. Ho, 2006: Radiative effect of cirrus with different optical properties over the tropics in MODIS and CERES observations. Geophys. Res. Lett., 33, L21811, https:// doi.org/10.1029/2006GL027403.

—— -, and C.-H. Sui, 2005: Different optical properties of high cloud in GMS and MODIS observations. Geophys. Res. Lett., 32, L23823, https://doi.org/10.1029/2005GL024616.

—, W. Kim, S.-W. Yeh, H. Masunaga, M.-J. Kwon, H.-S. Jo, and L. Huang, 2017: Revisiting the iris effect of tropical cirrus clouds with TRMM and A-Train satellite data. J. Geophys. Res., 122, 5917-5931, https://doi.org/10.1002/2016JD025827.

Cox, P. M., C. Huntingford, and M. S. Williamson, 2018: Emergent constraint on equilibrium climate sensitivity from global temperature variability. Nature, 553, 319-322, https://doi.org/ 10.1038/nature25450.

Danabasoglu, G., and P. R. Gent, 2009: Equilibrium climate sensitivity: Is it accurate to use a slab ocean model? J. Climate, 22 2494-2499, https://doi.org/10.1175/2008JCLI2596.1.

Emanuel, K., A. A. Wing, and E. M. Vincent, 2014: Radiativeconvective instability. J. Adv. Model. Earth Syst., 6, 75-90, https://doi.org/10.1002/2013MS000270.

Flato, G., and Coauthors, 2013: Evaluation of climate models Climate Change 2013: The Physical Science Basis, T. F. Stocker et al., Eds., Cambridge University Press, 741-866.

Fu, Q., and K. N. Liou, 1993: Parameterization of the radiative properties of cirrus clouds. J. Atmos. Sci, 50, 2008-2025, https:// doi.org/10.1175/1520-0469(1993)050<2008:POTRPO > 2.0.CO;2.

Gettelman, A., and S. C. Sherwood, 2016: Processes responsible for cloud feedback. Curr. Climate Change Rep., 2, 179-189, https://doi.org/10.1007/s40641-016-0052-8.

_ H. Morrison, and S. J. Ghan, 2008: A new two-moment bulk stratiform cloud microphysics scheme in the Community Atmosphere Model, version 3 (CAM3). Part II: Single-column and global results. J. Climate, 21, 3660-3679, https://doi.org/ 10.1175/2008JCLI2116.1.

— , and Coauthors, 2010: Global simulations of ice nucleation and ice supersaturation with an improved cloud scheme in the Community Atmosphere Model. J. Geophys. Res., 115, D18216, https://doi.org/10.1029/2009JD013797.

Hartmann, D. L., and K. Larson, 2002: An important constraint on tropical cloud-climate feedback. Geophys. Res. Lett., 29, 1951, https://doi.org/10.1029/2002GL015835.

_ , and M. L. Michelsen, 2002: No evidence for iris. Bull. Amer. Meteor. Soc., 83, 249-254, https://doi.org/10.1175/1520-0477(2002) $083<0249$ :NEFI $>2.3$.CO;2.

— tropical anvil clouds. J. Geophys. Res. Atmos., 122, 5003-5020, https://doi.org/10.1002/2017JD026460.

Houze, R. A., Jr., 1982: Cloud clusters and large-scale vertical motions in the tropics. J. Meteor. Soc. Japan, 60, 396-410, https://doi.org/10.2151/jmsj1965.60.1_396.

Hurrell, J. W., and Coauthors, 2013: The Community Earth System Model: A framework for collaborative research. Bull. Amer. Meteor. Soc., 94, 1339-1360, https://doi.org/10.1175/BAMS-D12-00121.1.

Iacono, M. J., J. S. Delamere, E. J. Mlawer, M. W. Shephard, S. A. Clough, and W. D. Collins, 2008: Radiative forcing by longlived greenhouse gases: Calculations with the AER radiative transfer models. J. Geophys. Res., 113, D13103, https://doi.org/ 10.1029/2008JD009944.

Kiehl, J. T., C. A. Shields, J. J. Hack, and W. D. Collins, 2006: The climate sensitivity of the Community Climate System Model version 3 (CCSM3). J. Climate, 19, 2584-2596, https://doi.org/ 10.1175/JCLI3747.1

Klein, S. A., A. Hall, J. R. Norris, and R. Pincus, 2017: Low-cloud feedbacks from cloud-controlling factors: A review. Surv. Geophys., 38, 1307-1329, https://doi.org/10.1007/s10712-0179433-3.

Kubar, T. L., D. E. Waliser, and J. Li, 2011: Boundary layer and cloud structure controls on tropical low cloud cover using ATrain satellite data and ECMWF analyses. J. Climate, 24, 194215, https://doi.org/10.1175/2010JCLI3702.1. 
Lin, B., B. A. Wielicki, L. H. Chambers, Y. Hu, and K. Xu, 2002: The iris hypothesis: A negative or positive cloud feedback? J. Climate, 15, 3-7, https://doi.org/10.1175/1520-0442(2002) 015<0003:TIHANO $>2.0 . \mathrm{CO} ; 2$.

Lindzen, R. S., M. Chou, and A. Y. Hou, 2001: Does the Earth have an adaptive infrared iris? Bull. Amer. Meteor. Soc., 82, 417432, https://doi.org/10.1175/1520-0477(2001)082<0417: DTEHAA $>2.3 . \mathrm{CO} ; 2$.

Loeb, N. G., and Coauthors, 2018: Clouds and the Earth's Radiant Energy System (CERES) Energy Balanced and Filled (EBAF) top-of-atmosphere (TOA) edition-4.0 data product. J. Climate, 31, 895-918, https://doi.org/10.1175/JCLI-D-170208.1.

Lord, S. J., W. C. Chao, and A. Arakawa, 1982: Interaction of a cumulus cloud ensemble with the large-scale environment. Part IV: The discrete model. J. Atmos. Sci., 39, 104113, https://doi.org/10.1175/1520-0469(1982)039<0104: IOACCE $>2.0 . \mathrm{CO} ; 2$.

Lu, J., G. A. Vecchi, and T. Reichler, 2007: Expansion of the Hadley cell under global warming. Geophys. Res. Lett., 34, L06805, https://doi.org/10.1029/2006G1028443.

Mauritsen, T., and B. Stevens, 2015: Missing iris-effect as a possible cause of high climate sensitivity in models. Nat. Geosci., 8 , 346-351, https://doi.org/10.1038/ngeo2414.

_ , and Coauthors, 2012: Tuning the climate of a global model. J. Adv. Model. Earth Syst., 4, M00A01, https://doi.org/10.1029/ 2012MS000154.

Morrison, H., and A. Gettelman, 2008: A new two-moment bulk stratiform cloud microphysics scheme in the Community Atmosphere Model, version 3 (CAM3). Part I: Description and numerical tests. J. Climate, 21, 3642-3659, https://doi.org/ 10.1175/2008JCLI2105.1.

Muller, C., and S. Bony, 2015: What favors convective aggregation and why? Geophys. Res. Lett., 42, 5626-5634, https://doi.org/ 10.1002/2015GL064260.

Neale, R. B., J. H. Richter, and M. Jochum, 2008: The impact of convection on ENSO: From a delayed oscillator to a series of events. J. Climate, 21, 5904-5924, https://doi.org/10.1175/ 2008JCLI2244.1.

Norris, J. R., R. J. Allen, A. T. Evan, M. D. Zelinka, C. W. O’Dell, and S. A. Klein, 2016: Evidence for climate change in the satellite cloud record. Nature, 536, 72-75, https://doi.org/ 10.1038/nature18273.

Park, S., and C. S. Bretherton, 2009: The University of Washington shallow convection and moist turbulence schemes and their impact on climate simulations with the Community Atmosphere Model. J. Climate, 22, 3449-3469, https://doi.org/ 10.1175/2008JCLI2557.1.

__, _ _ and P. J. Rasch, 2014: Integrating cloud processes in the Community Atmosphere Model, version 5. J. Climate, 27, 6821-6856, https://doi.org/10.1175/JCLI-D-14-00087.1.

Pincus, R., S. Platnick, S. A. Ackerman, R. S. Hemler, and R. J. Patrick Hofmann, 2012: Reconciling simulated and observed views of clouds: MODIS, ISCCP, and the limits of instrument simulators. J. Climate, 25, 4699-4720, https://doi.org/10.1175/ JCLI-D-11-00267.1.

Rapp, A. D., C. Kummerow, W. Berg, and B. Griffith, 2005: An evaluation of the proposed mechanism of the adaptive infrared iris hypothesis using TRMM VIRS and PR measurements. J. Climate, 18, 4185-4194, https://doi.org/10.1175/ JCLI3528.1.

Richter, J. H., A. Solomon, and J. T. Bacmeister, 2014: Effects of vertical resolution and nonorographic gravity wave drag on the simulated climate in the Community Atmosphere Model, version 5. J. Adv. Model. Earth Syst., 6, 357-383, https:// doi.org/10.1002/2013MS000303.

Rondanelli, R., and R. S. Lindzen, 2010: Comment on "Variations of tropical upper tropospheric clouds with sea surface temperature and implications for radiative effects" by $\mathrm{H}$. Su et al. J. Geophys. Res., 115, D06202, https://doi.org/10.1029/ 2008JD011189.

Satoh, M., S. Iga, H. Tomita, Y. Tsushima, and A. T. Noda, 2012: Response of upper clouds due to global warming tested by a global atmospheric model with explicit cloud processes. J. Climate, 25, 2178-2191, https://doi.org/10.1175/JCLI-D-1100152.1.

Schiffer, R. A., and W. B. Rossow, 1983: The International Satellite Cloud Climatology Project (ISCCP): The first project of the World Climate Research Program. Bull. Amer. Meteor. Soc., 64, 779-784, https://doi.org/10.1175/1520-0477-64.7.779.

Schiller, C., M. Krämer, A. Afchine, N. Spelten, and N. Sitnikov, 2008: Ice water content of Arctic, midlatitude, and tropical cirrus. J. Geophys. Res., 113, D24208, https://doi.org/10.1029/ 2008JD010342.

Seiki, T., C. Kodama, M. Satoh, T. Hashino, Y. Hagihara, and H. Okamoto, 2015: Vertical grid spacing necessary for simulating tropical cirrus clouds with a high-resolution atmospheric general circulation model. Geophys. Res. Lett., 42, 4150-4157, https://doi.org/10.1002/2015GL064282.

Shell, K. M., J. T. Kiehl, and C. A. Shields, 2008: Using the radiative kernel technique to calculate climate feedbacks in NCAR's Community Atmospheric Model. J. Climate, 21, 2269-2282, https://doi.org/10.1175/2007JCLI2044.1.

Sherwood, S. C., S. Bony, and J.-L. Dufresne, 2014: Spread in model climate sensitivity traced to atmospheric convective mixing. Nature, 505, 37-42, https://doi.org/10.1038/nature12829.

Slingo, J. M., 1987: The development and verification of a cloud prediction scheme for the ECMWF model. Quart. J. Roy. Meteor. Soc., 113, 899-927, https://doi.org/10.1002/ qj.49711347710.

Soden, B. J., and I. M. Held, 2006: An assessment of climate feedbacks in coupled ocean-atmosphere models. J. Climate, 19, 3354-3360, https://doi.org/10.1175/JCLI3799.1.

,,- R. Colman, K. M. Shell, J. T. Kiehl, and C. A. Shields, 2008: Quantifying climate feedbacks using radiative kernels. J. Climate, 21, 3504-3520, https://doi.org/10.1175/ 2007JCLI2110.1.

Song, X., G. J. Zhang, and J. F. Li, 2012: Evaluation of microphysics parameterization for convective clouds in the NCAR Community Atmosphere Model CAM5. J. Climate, 25, 85688590, https://doi.org/10.1175/JCLI-D-11-00563.1.

Storelvmo, T., I. Tan, and A. Korolev, 2015: Cloud phase changes induced by $\mathrm{CO}_{2}$ warming-A powerful yet poorly constrained cloud-climate feedback. Curr. Climate Change Rep., 1, 288296, https://doi.org/10.1007/s40641-015-0026-2.

$\mathrm{Su}, \mathrm{H}$., and Coauthors, 2008: Variations of tropical upper tropospheric clouds with sea surface temperature and implications for radiative effects. J. Geophys. Res., 113, D10211, https:// doi.org/10.1029/2007JD009624.

Taylor, K. E., R. J. Stouffer, and G. A. Meehl, 2012: An overview of CMIP5 and the experiment design. Bull. Amer. Meteor. Soc., 93, 485-498, https://doi.org/10.1175/BAMS-D-11-00094.1.

Thompson, D. W. J., S. Bony, and Y. Li, 2017: Thermodynamic constraint on the depth of the global tropospheric circulation. Proc. Natl. Acad. Sci. USA, 114, 8181-8186, https://doi.org/ 10.1073/pnas.1620493114. 
Tobin, I., S. Bony, and R. Roca, 2012: Observational evidence for relationships between the degree of aggregation of deep convection, water vapor, surface fluxes, and radiation. J. Climate, 25, 6885-6904, https://doi.org/10.1175/JCLI-D-1100258.1.

Wall, C. J., and D. L. Hartmann, 2018: Balanced cloud radiative effects across a range of dynamical conditions over the tropical west Pacific. Geophys. Res. Lett., 45, 11 490-11498, https:// doi.org/10.1029/2018GL080046.

, _ - M. M. Thieman, W. L. Smith, and P. Minnis, 2018: The life cycle of anvil clouds and the top-of-atmosphere radiation balance over the tropical west Pacific. J. Climate, 31, 10059 10 080, https://doi.org/10.1175/JCLI-D-18-0154.1.

Wetherald, R. T., and S. Manabe, 1980: Cloud cover and climate sensitivity. J. Atmos. Sci., 37, 1485-1510, https://doi.org/ 10.1175/1520-0469(1980)037<1485:CCACS > 2.0.CO;2.

Wilson, D. R., and S. P. Ballard, 1999: A microphysically based precipitation scheme for the UK Meteorological Office Unified Model. Quart. J. Roy. Meteor. Soc., 125, 1607-1636, https://doi.org/10.1002/qj.49712555707.

Wing, A. A., and K. A. Emanuel, 2014: Physical mechanisms controlling self-aggregation of convection in idealized numerical modeling simulations. J. Adv. Model. Earth Syst., 6, 59-74, https://doi.org/10.1002/2013MS000269.
,-- C. E. Holloway, and C. Muller, 2017: Convective selfaggregation in numerical simulations: A review. Surv. Geophys., 38, 1173-1197, https://doi.org/10.1007/s10712-017-9408-4.

Wood, R., and P. R. Field, 2000: Relationships between total water, condensed water, and cloud fraction in stratiform clouds examined using aircraft data. J. Atmos. Sci., 57, 1888-1905, https://doi.org/ 10.1175/1520-0469(2000)057<1888:RBTWCW >2.0.CO;2.

Zelinka, M. D., S. A. Klein, and D. L. Hartmann, 2012a: Computing and partitioning cloud feedbacks using cloud property histograms. Part I: Cloud radiative kernels. J. Climate, 25, 3715-3735, https://doi.org/10.1175/JCLI-D-11-00248.1.

$\ldots, \ldots$, and $\_, 2012 \mathrm{~b}$ : Computing and partitioning cloud feedbacks using cloud property histograms. Part II: Attribution to changes in cloud amount, altitude, and optical depth. J. Climate, 25, 3736-3754, https://doi.org/10.1175/JCLI-D-1100249.1.

— C. Zhou, and S. A. Klein, 2016: Insights from a refined decomposition of cloud feedbacks. Geophys. Res. Lett., 43, 92599269, https://doi.org/10.1002/2016GL069917.

Zhang, G. J., and N. A. McFarlane, 1995: Sensitivity of climate simulations to the parameterization of cumulus convection in the Canadian Climate Centre general circulation model. Atmos.-Ocean, 33, 407-446, https://doi.org/10.1080/ 07055900.1995.9649539. 